\title{
The Combined Effects of Destructive and Constructive Leadership on Thriving at Work and Behavioral Empowerment
}

\section{Léandre Alexis Chénard-Poirier ${ }^{\mathrm{a}}$, Alexandre J.S. Morin ${ }^{\mathrm{b}}$, Jean-Sébastien Boudrias ${ }^{\mathrm{c}}, \boldsymbol{\&}$ Nicolas Gillet $^{\text {d }}$}

\author{
${ }^{a}$ Laboratoire de Recherche sur le Comportement Social, Département de psychologie, Université du \\ Québec à Montréal, Montréal, Canada \\ ${ }^{\mathrm{b}}$ Substantive-Methodological Synergy Research Laboratory, Department of Psychology, Concordia \\ University, Montreal, Canada \\ ${ }^{\mathrm{c}}$ Département de psychologie, Université de Montréal, Montréal, Canada \\ dQualiPsy, Département de psychologie, Université de Tours; Institut Universitaire de France (IUF), \\ Tours, France
}

This is the final prepublication version of :

Chénard-Poirier, L.A., Morin, A.J.S., Boudrias, J.-S., \& Gillet, N. (2021). The combined effects of destructive and constructive leadership on thriving at work and behavioral empowerment. Journal of Business and Psychology. https://doi.org/10.1007/s10869-021-09734-7

(C) 2021. This paper is not the copy of record and may not exactly replicate the authoritative document published in Journal of Business and Psychology.

Correspondence concerning this article should be addressed to:

Léandre Alexis Chénard-Poirier (Ph. D.)

Laboratoire de recherche sur le comportement social

Département de psychologie

Université du Québec à Montréal

P.O. Box 8888, Station Centre-Ville

Montreal (Quebec) H3C 3P8

Canada

Email: leandre.chenard.poirier@gmail.com

\begin{abstract}
This study investigates the within-domain exacerbation phenomenon in relation to employees' perception of their supervisors' leadership behaviors. This phenomenon proposes that exposure to supervisors relying on a combination of destructive leadership behaviors (DLB; operationalized as petty tyranny) and constructive leadership behaviors (CLB; operationalized as transformational leadership) should have more negative consequences on followers' levels of thriving and behavioral empowerment than exposure to supervisors relying more exclusively on DLB or CLB. This phenomenon was tested using a person-centered mixture regression approach with a sample of 2104 Canadian employees from a police organization. Three profiles of employees were identified, representing those exposed to Moderately Transformational (mostly CLB), Destructive (mostly DLB) and Inconsistent (CLB and DLB) supervisors. Members of the Inconsistent profile displayed the lowest levels of thriving and behavioral empowerment, followed by members of the Destructive profile, and finally by members of the Moderately Transformational profile. Results also suggest that the inability to determine if a supervisor is more destructive or constructive might explain the within-domain exacerbation phenomenon. Indeed, in the Inconsistent profile, leadership clarification seemed beneficial for employees. Increases in DLB resulted in a matching increase in empowered behaviors centered on the group and organization, while increases in CLB resulted in increases in thriving and empowered behaviors centered on individual performance.
\end{abstract}

Key words: Within-domain exacerbation; petty tyranny; transformational leadership; thriving at work; behavioral empowerment; person-centered analysis 


\section{Introduction}

Destructive leadership behaviors (DLB) refer to methods of influence directed toward followers and perceived as a sustained display of hostility and/or obstructiveness (Schyns \& Schilling, 2013). As a broad category, DLB have fallen under different headings such as abusive supervision (Tepper, 2000, 2007), petty tyranny (Ashforth, 1994, 1997) and social undermining (Duffy et al., 2002). Exposure to DLB has been found to predict lower levels of performance and organizational citizenship behaviors, family and life satisfaction, and work attitudes such as commitment and job satisfaction (Mackey et al., 2017). Likewise, DLB has been shown to predict a variety of undesirable outcomes such as stress, negative emotions, counterproductive work behaviors, and turnover intentions (Schyns \& Schilling, 2013).

The majority of research on DLB has focused on evaluating the negative consequences associated with exposure to such behaviors among followers, without simultaneously considering the role played by constructive leadership behaviors (CLB). CLB refer to behaviors aimed at attaining organizational goals and improving employees' motivation, well-being, and satisfaction (Aasland et al., 2010). By separately considering the effects of DLB and CLB, past research has thus indirectly implied that supervisors should present leadership profiles that are either good or bad. By leadership profile, we refer to the specific configuration, or pattern, of leadership behaviors generally displayed by a specific type of supervisors, in a way that makes this type of supervisor distinct from other types of supervisors. Acknowledging this limited perspective led some scholars to underscore the need to better position DLB in relation to CLB for two reasons (Einarsen et al., 2010; Tepper et al., 2017). First, there is growing evidence that supervisors cannot be described in such a good or bad manner, but rather that many supervisors tend to exhibit a combination of DLB and CLB. Second, the within-domain exacerbation phenomenon counterintuitively suggests that supervisors displaying such a mixed profile of leadership (combining DLB and CLB) might have more negative consequences on followers than purely destructive supervisors.

First, when considering the ever-changing and highly stressful work environment where many supervisors have to operate on a daily basis (Sparks et al., 2001), some generally constructive leaders may come to offer harsh and unjustified critics or reprimands toward their employees as a result of selfregulation impairments resulting from overwhelming job demands (e.g., Byrne et al., 2014; Collins \& Jackson, 2015). Likewise, supervisors with clear dispositions toward DLB, such as leaders characterized by high levels of Machiavellianism (Kiazad et al., 2010) or psychopathy (Mathieu \& Bibiak, 2016), may sometimes rely on positive motivational strategies, perhaps as an attempt to manipulate their employees to help them achieve their personal objectives. In both situations, employees would face a supervisor with a leadership profile that combines DLB and CLB.

Second, although mainstream theories of leadership generally argue for the presence of linear relations between DLB or CLB and employee outcomes (e.g., social exchange theory; Cropanzano et al., 2017), these theories fail to address the combined role played by DLB and CLB. The within-domain exacerbation phenomenon provides an alternative perspective on the possible role played by this combination. Indeed, this theoretical mechanism suggests that exposure to a supervisor who is relying on behaviors that are seen as being both stressful (i.e., DLB) and supportive (i.e., CLB) should be even more harmful for subordinates than exposure to a supervisor consistently perceived as a source of stress (Duffy et al., 2002; Hobman et al., 2009; Major \& Zubek, 1997). This counterintuitive perspective thus suggests that the most deleterious type of supervisor might not be those who systematically rely on DLB, but rather those that present a more nuanced leadership profile characterized by a mixture of DLB and CLB. What is particularly concerning is that these leaders might seemingly appear as a less salient threat for employees, due to their more nuanced adoption of CLB and DLB. Consequently, they might "fall under the radar" in the context of organizational efforts seeking to improve leadership practices among supervisors. Therefore, documenting the existence, nature, and implications of these combined leadership profiles appears to be of the utmost importance for organizations seeking to support employees' well-being and performance.

The present study has two objectives. First, it takes a first step at investigating whether some supervisors display a leadership profile characterized by combinations of DLB and CLB. To do so, this study considers two widely investigated types of leadership with well-established destructive and constructive outcomes, petty tyranny (Ashforth, 1994, 1997) and transformational leadership (Bass \& Bass, 2008). Second, assuming the identification of leadership profiles displaying such a combination, 
this study seeks to expand knowledge on within-domain exacerbation in the leadership literature by examining the joint effects these antagonistic behaviors on two work-related outcomes encompassing employees' well-being (thriving at work) and work-related behaviors (behavioral empowerment). To do so, we rely on an emerging hybrid mixture regression approach (Chénard-Poirier et al., 2017; Gillet et al., 2018) which provides a way to simultaneously meet both objectives, namely: (a) identifying leadership profiles characterized by distinct CLB/DLB combinations while also (b) considering how these profiles differ in their patterns of associations between CLB/DLB and employees' levels of thriving and behavioral empowerment.

\section{Petty Tyranny and Transformational Leadership}

Petty tyranny and transformational leadership are two antagonistic types of leadership behaviors that respectively fall into the categories of DLB and CLB. Petty tyranny refers to leadership behaviors considered to be oppressive, capricious, and vindictive, which makes them a high source of strain for exposed followers (Ashforth, 1994, 1997). It encompasses hostile behaviors such as belittling, arbitrariness, and non-contingent punishment. In contrast, transformational leadership is known to be one of the most potent forms of CLB (Aasland et al., 2010) and its positive influence on followers has been extensively demonstrated (Hoch et al., 2018; Wang et al., 2011). Transformational leadership refers to behaviors aiming to motivate followers to go beyond their personal interest and to work collectively toward organizational goals (Bass \& Riggio, 2006). It encompasses behaviors such as intellectual stimulation, inspirational motivation, idealized influence, and individualized consideration.

\section{Thriving and Behavioral Empowerment}

Employee's thriving and behavioral empowerment represent attitudinal and behavioral desirable consequences of leadership (i.e., they are thus at least partially under the supervisor control), which allow employees to achieve organizational objectives. Thriving is a construct that captures feelings of energy and perceptions of personal growth at work, through vitality and learning (Spreitzer et al., 2005). Thriving is seen as a key determinant of psychological well-being at work, and as being associated with lower levels of job strain and burnout (Porath et al., 2011). Thriving therefore reflects the extent to which an employee is energized by, and able to grow within, his/her work context and supervision. Behavioral empowerment focuses on employees' behavioral efforts to achieve organizational objectives. These behaviors are known to be displayed by motivated employees exposed to constructive leaders (Kim et al., 2018; Pigeon et al., 2017). It encompasses a set of active autonomous in-role and extra-role behaviors aiming to ensure and to improve performance at the individual, group, and organization levels (Boudrias et al., 2014). They include the efficient performance of one's tasks, efforts at improving the way one's job tasks are completed, effective collaboration at the workgroup-level, efforts to improve workgroup functioning, and involvement at the organizational level.

\section{The Isolated Effects of Petty Tyranny and Transformational Leadership}

In essence, the theoretical underpinnings explaining the differential effects of tyrannical leadership and transformational leadership suggest that while the former tends to undermine social exchanges with the supervisor, in turn impeding employees' well-being and empowered behaviors, the latter tends to have the opposite effects (Cropanzano et al., 2017).

DLB such as petty tyranny elicit among subordinates distrust, anxiety, and fear with regard to their exchanges with the supervisor (Chan \& McAllister, 2014), psychological states which are incompatible with thriving. It also elicits a desire to retaliate through decreased efforts at work (Cropanzano et al., 2017). In addition, DLB have been shown to be disempowering, as they tend to be associated with lower perceptions of psychological empowerment (i.e., meaning, autonomy, selfefficacy and impact at work; Lyu et al., 2019) among employees, a psychological state mediating the relation between supervisory behaviors and employees' behavioral empowerment efforts (Boudrias et al., 2009)

Conversely, transformational leadership has been shown to help foster positive social exchanges between employees and supervisors (Wang et al., 2005), in turn leading to greater levels of energy, learning, and thriving among subordinates (Hildenbrand et al., 2018; Niessen et al., 2017). It has also been shown to fosters empowerment among employees and to sustain a desire to reciprocate via higher levels of behavioral efforts at work (Seibert et al., 2011).

When displayed by a single supervisor over time, petty tyranny and transformational leadership send contradictory messages to followers. Thus, the goals of this research are to study whether or not specific leadership profiles are characterized by a combination of these behaviors, and to analyse the 
relations between such leadership profiles and employees' thriving and behavioral empowerment. In doing so, this research goes further than providing a picture of the respective direct effects of DLB and CLB.

\section{Can Supervisors Exhibit Combinations of DLB and CLB?}

Research has shown that DLB and CLB are empirically distinct constructs (Schriesheim et al., 1976) and that supervisors do not always act in a fully consistent manner toward their employees (e.g., Duffy et al., 2002; Lian et al., 2012; Rayner \& Cooper, 2003). For example, Matta et al. (2017) showed that the same supervisor can display fairness to employees one day, and unfairness another day. Central to this inconsistency is the idea that whether a supervisor display DLB or CLB may not be entirely intentional or the sole product of dispositional traits, but might also depend on external factors that affect a leader's ability to regulate his or her behaviors (Byrne et al., 2014; Collins \& Jackson, 2015). For instance, research has shown self-regulation abilities to be relevant for the successful implementation of CLB, such as transformational leadership (Collins \& Jackson, 2015; Olsen et al., 2016).

Focusing on DLB, Wang et al. (2010) proposed that environmental stressors could momentarily deplete a leader's ability to regulate his/her affective reactions, leaving him/her more susceptible to counterproductive social interactions with subordinates. More precisely, workplace stressors tend to generate negative emotions such as anger, frustration, or anxiety, which in turn may increase the probability that a supervisor will act upon these negative emotions through DLB. As self-regulation operates on the basis of a limited resource system (Baumeister et al., 2006), external contingencies (such as exposure to stressors) may lead to the depletion of the emotional resources required by supervisors to refrain from acting on these negative emotions via DLB. Consistent with this idea, studies have shown that the stress induced by overwhelmingly difficult goals (Mawritz et al., 2014) or role overload (Eissa \& Lester, 2017) was associated with an increase in negative emotions among supervisors which, in turn, led them to rely on higher levels of DLB. More generally, Krasikova et al. (2013) proposed that any stressors seen as interfering with the achievement of supervisors' goals might also directly lead them to rely on DLB as a way to restore goal attainment, while acknowledging the possible amplificatory role of self-regulatory deficits on this relation.

In sum, depending on how demanding a supervisor's work environment is, the same leader might sometimes rely on DLB as a result of a higher stress and impaired self-regulation abilities, while remaining able to maintain and implement CLB during quieter periods. From the perspective of the followers who may not necessarily have access to the full range of work conditions to which the supervisor is exposed on a daily basis, these supervisors may be seen as presenting a leadership profile that combines both constructive and destructive behaviors.

It is important to acknowledge that this self-regulatory pathway is only one of the mechanisms which has been proposed to explain why some supervisors may come to rely on DLB and CLB combinations. For example, some have argued that supervisors presenting personality predispositions to DLB (e.g. Machiavellianism or psychopathy) may be forced to refrain from using such behaviors too often and to implement more constructive ones in positive environments (Furtner et al., 2017). Conversely, these same supervisors might act in a more consistently destructive manner in environments where aggressive norms prevail and where such behaviors are not sanctioned (Zhang \& Bednall, 2016). In such environments, DLB may even come to be seen as an effective way to lead (Hu \& Liu, 2017; Restubog et al., 2011). Similar rationales can be proposed for CLB. For instance, supervisors presenting more constructive dispositions, such as those displaying high levels of agreeableness (Bono et Judge, 2004) or emotional intelligence (Harms \& Credé, 2010), may be encouraged to combine some DLB to their CLB in more aggressive work contexts, as a result of a social learning process (Wang et al. 2010).

On the basis of these propositions, this study seeks to verify whether some leaders do indeed combine DLB (such as petty tyranny) and CLB (such as transformational leadership) in the leadership profile that they present to their employees. More precisely, the present study proposes to explore the following research question:

RQ1: Can supervisors rely on combinations of DLB and CLB?

\section{The Within-Domain Exacerbation Phenomenon}

Assuming that DLB (i.e., petty tyranny) and CLB (i.e., transformational leadership) can coexist in a same leadership profile, the within-domain exacerbation phenomenon proposes that such combination would be more harmful for employees than a more consistently destructive leadership profile. More precisely, the within-domain exacerbation phenomenon states that when a person's (such 
as a supervisor) behaviors are considered to be a stressor for another person (such as a subordinate), socially supportive behaviors from that same person (i.e., within-domain) is likely to amplify these adverse effects rather than to attenuate them (Duffy et al., 2002; Hobman et al., 2009; Major et al., 1997). This phenomenon thus proposes that supervisors presenting a profile combining stressful behaviors (e.g., petty tyranny) and supportive behaviors (e.g., transformational leadership) should have more negative consequences for employees' well-being and performance than supervisors presenting a profile more consistently seen as a source of stress or support.

To our knowledge, few studies have so far found evidence for the within-domain exacerbation phenomenon in the context of supervisor-subordinate relationships. First, Duffy et al. (2002) showed that supervisors' undermining behaviors tended to be more negatively related to subordinates' levels of self-efficacy, commitment, and well-being, and more positively related to their levels of counterproductive work behaviors, when supervisors were simultaneously perceived as supportive. Exposure to supervisors seen as both undermining and supportive was also related to higher job-strain and lower perceived health (Nahum-Shani et al., 2014), as well as to higher levels of stress (Herr et al., 2018). Similarly, Lian et al. (2012) and Xu et al. (2015) respectively found that the negative consequences of DLB on employees' basic needs satisfaction at work and emotional exhaustion were exacerbated when they occurred in the context of high-quality relationships.

In sum, evidence of within-domain exacerbation should come from the observation of one or more leadership profiles characterized by matching levels of tyrannical and transformational behaviors, and associated with lower levels of thriving and behavioral empowerment relative to profiles more clearly dominated by DLB. In this regard, tentative evidence from the limited amount of research conducted so far lead us to expect that:

H1: Employees exposed to supervisors relying on a combination of petty tyranny and transformational leadership should experience lower levels of thriving at work than employees exposed to supervisors relying mainly on petty tyranny.

H2: Employees exposed to supervisors relying on a combination of petty tyranny and transformational leadership should display lower levels of behavioral empowerment than employees exposed to supervisors relying mainly on petty tyranny.

\section{The Uncertainty Mechanism}

The within-domain exacerbation phenomenon stems from the negativity dominance principle, according to which "combinations of negative and positive entities yield evaluations that are more negative than the algebraic sum of individual subjective valences would predict" (Rozin \& Royzman, 2001, p. 296). Further, it has been theoretically proposed that this phenomenon might be explained by uncertainty management theory (Lind \& van den Bos, 2002). According to this theory, employees strive to feel certainty about their world and their place in it (Lind \& van den Bos, 2002). Uncertainty arises when employees have difficulty to predict their environment or face inconsistent cognitions, behaviors, or experiences. Therefore, this uncertainty mechanism implied by this theoretical framework suggests that exposure to a supervisor characterized by an inconsistent leadership profile (i.e., combining DLB and CLB) should be more stressful and harmful than exposure to a consistently destructive supervisor for two main reasons.

First, as a result of being exposed to inconsistent and hard to anticipate supervisory behaviors, employees may feel a sense of loss of control over their work environment (van den Bos \& Lind, 2002; Tan \& Lipe, 1997). Consistent leadership behaviors, whether they are constructive or destructive, allow employees to better anticipate their supervisors' reactions from one interaction to the other and thus gain control over their environment. On the contrary, for employees subjected to inconsistent leadership behaviors, anticipating whether their supervisor will act in a destructive or constructive manner might be more difficult as they know their leader is capable of both. Furthermore, considering the critical role of supervisors in shaping and guiding employees' work, inconsistent leadership behaviors may send mixed messages regarding what is valued in the organization (Mullen et al., 2011). For example, an inconsistent leader conveying incoherent messages to employees by sometimes motivating them to adopt organizational goals and supporting them (i.e., transformational leadership; Bass \& Bass, 2008), and at other times punishing them, offering destructive feedback and showing arbitrariness (i.e., petty tyranny; Ashforth, 1994, 1997), could hinder their perception of control and their ability to accomplish their work. In this context, employees would have more difficulty knowing what their goals are and how important they are. This perceived lack of control is likely to act as an important stressor for exposed 
employees (Breevaart \& Bakker, 2014; Sonnentag \& Frese, 2003), and likely to impede thriving (Spreitzer et al., 2005) and empowered behaviors (Spreitzer, 2008) as a sense of agency at work is a central condition to both.

Second, inconsistent supervisor behaviors create relational uncertainty (De Cremer, 2003), by informing followers that their relationship is unstable and malfunctioning (van den Bos \& Lind, 2002). Supervisors relying on a combination of CLB and DLB send conflicting messages to employees about their worth, the quality of their contribution, and the quality of their relationships with them. Multiple studies have shown that relationships seen as both aversive and supportive tend to be more stressful than consistently aversive ones (Herr et al., 2018; Holt-Lunstad et al., 2003; Uchino et al., 2001). In addition, mixed messages can thwart employees' need to experience a coherent sense of self, leading to feelings of self-uncertainty (De Cremer, 2003; Lind \& van den Bos, 2002; Nahum-Shani et al., 2014; Swann et al., 2003), that could further impede thriving and empowered behaviors.

As a result of this loss of control and relational uncertainty, employees may become even more vigilant and reactive to any information regarding the unfairness of their treatment, including their supervisor's occasional reliance on DLB (Proudfoot \& Lind, 2015). In contrast, employees may habituate to a more consistently destructive supervisor by adopting effective coping strategies, such as social support, avoidance or resistance, that might in turn help to attenuate their level of stress (Aquino \& Thau, 2009; Frieder et al., 2015; Harvey et al., 2007), the negative impact of DLB on their performance (Tepper et al., 2017), and help them preserve their self-esteem (Vogel \& Mitchell, 2017). In contrast, employees exposed to supervisors that are not clearly destructive or constructive might have more difficulty in developing effective coping strategies or may come to adopt strategies not directly related to the threat, such as trying to make sense of the situation (van Harreveld et al., 2015).

More specifically, the uncertainty mechanism suggests that any increase in petty tyranny or transformational leadership occurring in a profile characterized by a combination of petty tyranny and transformational leadership should be related to increases in thriving and behavioral empowerment by increasing the certainty of supervisors' behaviors. However, lacking clear empirical guidance in this regard, we extend previous research by considering the following research question:

RQ2: Is the within-domain exacerbation phenomenon underpinned by the uncertainty mechanism?

\section{A Hybrid Approach to Test the Within-Domain Exacerbation Mechanism}

Although variable-centered methods used in previous studies of the within-domain exacerbation phenomenon provide useful information, they are insufficient to identify DLB and CLB combinations, to achieve a comprehensive overview of the mechanism involved in these effects, and to determine whether the mechanism equally apply to all employees. Variable-centered analyses assess relations between variables as they occur, on the average, in the sample under study, and fail to consider the possibility that different leadership profiles might exist in this sample. It is true that tests of interactions provide a way to observe whether the effects of one variable change as a function of another. However, tests of interactions rely on an assumption of linearity (i.e., the effects of each variable are assumed to change linearly as a function of the other). Polynomial models make it possible to incorporate non-linear relations (Edwards, 2009), but considerably add the complexity of the analyses and of their interpretations. Still, even polynomial models rely on the assumption that the observed effects would apply equally to all employees (i.e., that the mechanism apply equally to everyone).

Person-centered analyses, such as latent profile analyses (LPA), rather seek to identify groups of workers characterized by distinct configurations, or profiles, on a set of variables. They are thus naturally suited to the investigation of the joint effect of variable combinations (Meyer \& Morin, 2016; Morin, 2016). LPA can be used to identify the most frequent combinations of DLB and CLB to which employees are typically exposed and assess the relative consequences of these combinations without relying on linearity assumptions. Yet, a key limitation of LPA is the failure to consider the possibility that relations between variables (the key component of variable-centered analyses) could differ across distinct groups of employees exposed to different leadership profiles (the key component of LPA). More advanced forms of person-centered analyses, such as mixture regression analyses, provide a way to identify profiles of workers whom relations between variables differ (Van Horn et al., 2009). Thus, rather than profiling participants based on their configuration on a series of indicators, mixture regression seeks to detect profiles characterized by different relations.

A hybrid mixture regression approach (e.g., Meyer \& Morin, 2016; Morin, 2016) has been 
proposed as a way to build bridges between variable-centered analyses, LPA, and mixture regression analyses. The applicability of this method has recently been highlighted in organizational research focusing on leadership (Chénard-Poirier et al., 2017). This hybrid approach provides a way to identify workers' profiles differing based on their specific configuration of scores on predictor variables (i.e., DLB and CLB) while simultaneously allowing relations between these predictors and outcomes to differ across profiles. These models are specifically designed to reveal complex interactions, resulting in profiles in which the relations between constructs differ (i.e., are moderated) as a function of variations in predictors' levels around profile-specific averages (e.g., Bauer, 2005). They are thus naturally suited to the investigation of the possible existence of DLB and CLB combinations and their relations with work-related outcomes. When compared to variable-centered tests of interactions, this hybrid approach has the advantage of assuming neither population homogeneity, nor linearity. When compared to LPA, this approach has the advantage of considering the possibility the associations between predictors and outcomes can change (i.e., moderated) as a function of profile membership. Finally, when compared to classical mixture regression, this approach has the advantage of allowing profiles to be defined based on both the combination of indicators (as in LPA) and their inter-relations (as in mixture regression).

This hybrid approach disaggregates the relations observed between CLB/DLB and outcomes into two distinct components (Chénard-Poirier et al., 2017). First, a between-profile component will provide a way to compare profiles based on the configuration of DLB and CLB to which workers are exposed, and thus provide a test of RQ1. It also provides a way to compare profiles on the basis of the outcome levels (i.e., the regression intercepts) observed in each profile, providing a test of $\mathrm{Hl}$ and $\mathrm{H} 2$. Indeed, allowing for the identification of the global shape of the relation occurring at the between-profile level between average predictor levels and average outcome levels also provides information regarding whether or not the profile is coherent with the within-domain exacerbation phenomenon $(\mathrm{Hl}$ and $\mathrm{H} 2)$.

Second, a within-profile component assesses the presence of residual associations between predictors and outcomes not explained by between-profile comparisons (i.e. associations between variations around the profile-averages). More precisely, this component assesses, using regression analysis, whether within-profile variations in DLB and CLB can add to the prediction of within-profile variations in outcome levels. This approach allows these within-profile associations to differ across profiles. Thus, it provides information about the mechanism involved, thus offering a direct test of the uncertainty mechanism (RQ2).

\section{Sample and Procedure}

\section{Methodology}

A sample of 2104 French Canadian employees from a police organization (61.3\% males) were recruited to participate in this study. Police organizations are a particularly suitable environment to the study of DLB, as they have a militaristic work organization characterized by a strict hierarchy and a culture where DLB are often considered to be an effective way to lead (Girodo, 1998; Hu \& Liu, 2017; Vito et al., 2011). Furthermore, the high-power asymmetry resulting from the police hierarchy helps to enable leaders with more destructive tendencies (Aryee et al., 2008).

Participants had the choice to respond to a paper-pencil or to an online questionnaire to evaluate their immediate supervisor's leadership and their own levels of thriving at work and behavioral empowerment. No incentive was offered. Participants were informed of the confidentiality of their individual responses and gave their informed consent prior to participation. A majority of the participants had completed a college education (CEGEP; $51.8 \%$ ), while $40.8 \%$ had a completed some university education, and $7.4 \%$ had less than a college degree. About half of participants were under 39 years-old $(53.1 \%)$. On average, participants reported working $35.60(S D=6.04)$ hours per week, which represents the regular full-time work week in this organization as well as across most organizations located in the Canadian province where the data was collected. They had $13.30(S D=8.44)$ years of tenure in their organization and $2.00(S D=2.35)$ years of tenure with their supervisor. Most participants $(92.3 \%)$ reported having been in their current position for one year or more and having daily $(70.8 \%)$ or weekly (23.6\%) contact with their supervisor. Most participants $(78.5 \%)$ were police officers, while the rest were administrative employees and parking officers. Demographic characteristics are presented in Table 1.

\section{Measures}

Leadership behaviors. Transformational leadership was assessed using the French version of the MLQ Form 5X-Short $(\alpha=.97$; Avolio \& Bass, 2004). The four dimensions covered in this 
questionnaire, idealized influenced ( 8 items; $\alpha=.93$; e.g., "My supervisor talks about their most important values and beliefs"), individual consideration (4 items; $\alpha=.87$; e.g., "My supervisor spends time teaching and coaching"), intellectual stimulation (4 items; $\alpha=.86$; e.g., "My supervisor seeks differing perspectives when solving problems"), and inspirational motivation ( 4 items; $\alpha=.87$, e.g., "My supervisor talks enthusiastically about what needs to be accomplished"), were used to represent a global construct.

Petty tyranny was assessed using the validated French version (Cacciatore, 2015; Cacciatore et al., 2010) of Ashforth's (1994) scale. Although, the initial petty tyranny scale comprised six dimensions, the validated French version $(\alpha=.95)$ incorporates three 4 items dimensions: arbitrariness and selfaggrandizement ( $\alpha=.90$, e.g., "My supervisor uses authority or position for personal gain"), noncontingent punishment ( $\alpha=.91$, e.g., "My supervisor is often displeased with my work for no apparent reason"), and belittling subordinates ( $\alpha=.90$, e.g., "My supervisor belittles or embarrasses subordinates"). These dimensions are used to reflect an overarching petty tyranny factor. According to Tepper (2007), some of the remaining dimensions did not directly capture DLB. For instance, lack of consideration, being hard to approach, discouraging initiative, or forcing conflict resolution, the other dimensions proposed by Ashforth (1994), are not necessarily considered as being actively hostile. All leadership items were rated on a 5-point scale ranging from 1 (never) to 5 (very frequently, if not always).

Thriving at work $(\alpha=.91)$ was assessed with the French version (Boudrias et al., 2015) of Porath et al.'s (2011) scale. The two dimensions, vitality (3 items; $\alpha=.89$, e.g., "I am looking forward to each new day") and learning at work ( 3 items; $\alpha=.83$, e.g., "I see myself continually improving"), were rated on a 7 -point scale ranging from 1 (strongly disagree) to a 7 (strongly agree) and were used to form a global thriving factor and.

Behavioral empowerment was assessed using Boudrias et al. (2010) scale. The five dimensions are each measured by three items referring to the employee's behaviors: efficacy in performing job tasks $(\alpha=.89$; e.g., "Adequately carry out the tasks related to my job"), improvement efforts in job tasks ( $\alpha=$ .90; e.g., "Put into practice my ideas for improvement in my work"), effective collaboration in the workgroup ( $\alpha=.78$; e.g., "Provide constructive feedback that helps my coworkers"), improvement efforts in the workgroup $(\alpha)=8$; e.g., "Introduce new ways of doing things in my workgroup"), and involvement at the organizational level ( $\alpha=.88$; e.g., "Make suggestions to improve the organization's functioning"). The empowerment behaviors were rated on a 10-point frequency scale ranging from 1 (almost never [0-10\% of possible occasions]) to 10 (almost always [90\%-100\% of possible occasions]). Validity evidence supports the a priori five-factor structure of this instrument (Lajoie et al., 2017).

Analyses

Analyses were conducted using Mplus 7.4's (Muthén \& Muthén, 2015) robust maximum likelihood estimator (MLR) and "complex" function, which provides standard errors, tests of statistical significance, and fit indices that are robust to non-normality and to the clustering of participants into 505 work units (e.g., Asparouhov, 2005; Marsh \& O'Mara, 2010). The limited number of missing responses $(1.59 \%$ to $4.48 \%)$ was handled using full information maximum likelihood (Enders, 2010).

Mixture regression analyses are based on factor scores saved from a preliminary measurement model, which indicates an excellent fit to the data $\left(\chi^{2}=3688.11 ; d f=1170\right.$; CFI $=.96$; TLI $=.95$; RMSEA = .03; Hu \& Bentler, 1999; Marsh et al., 2005). These factor scores are estimated in standardized units with $M=0$ and $S D=1$, and provide a partial control for measurement errors (Skrondal $\&$ Laake, 2001). Details on the measurement model are reported in the online supplements, and latent correlations are reported in Table 2.

Mixture regression analyses including one to eight profiles were estimated using 10,000 sets of random starts values, 1,000 iterations for each set, and allowed the 500 best sets to be used for final optimization in order to minimize the risk of converging on a suboptimal local solution (Hipp \& Bauer, 2006; Morin \& Wang, 2016). In these models, the means of the predictors, the means of the outcomes (i.e., the regression intercepts), the variance of the outcomes (i.e., the regression residuals, and thus the $\mathrm{R}^{2}$ ), and the regressions slopes were freely estimated in all profiles, while the variance of the predictors was constrained to equality across profiles.

The selection of the optimal number of profiles is based on the consideration of the theoretical meaning of the profiles, the statistical adequacy of the solution (Marsh et al., 2009; Muthén, 2002) and 
statistical indicators: (i) the Akaïke Information Criterion (AIC); (ii) the Consistent AIC (CAIC), (iii) the Bayesian Information Criterion (BIC), (iv) the Sample-size adjusted BIC (ABIC), (v) the adjusted Lo, Mendell and Rubin's (2001; aLMR) Likelihood Ratio Test. Lower values on the AIC, CAIC, BIC, and ABIC indicate a better-fitting model. A statistically significant $p$-value on the aLMR supports the model to which it is associated relative to a solution including one fewer profile. These tests frequently keep on suggesting the addition of profiles without reaching a minimum with sufficiently large samples (Marsh et al., 2009). When this happens, the point at which these indicators reach a plateau on a graphical display (elbow plot) can be used to suggest the optimal solution (Morin, 2016; Morin et al., 2011). Entropy is also reported and provides a useful summary of the accuracy of participants' classification into the profiles.

For description purposes, the following demographics were contrasted across profiles using the "auxiliary (e)" function: sex, supervisory role, age, education, frequency of contact with the immediate supervisor, weekly worked hours, and tenure with the organization, in its position, and with the supervisor. This function relies on a Wald-test of significance based on pseudo-class draws to contrast covariates without having to integrate them in the model (Asparouhov \& Muthén, 2007).

\section{Selection of the Optimal Number of Profiles}

\section{Results}

Fit indices for the mixture regression models including 1 to 8 profiles are reported in Table 3 . As anticipated, the information criteria failed to converge on a specific solution. However, the aLMR indicated that the retained solution would likely include a maximum of five profiles. When we consider the graphical display of the value of the information criteria (reported in Figure S1 of the online supplements), these indicators appear to reach a plateau between solutions including three and four profiles. When we carefully consider these specific solutions, the results showed that profiles were both theoretically meaningful and interpretable up to the three-profile solution. However, moving from three to four profiles did not add meaningful information, simply adding a very small profile $(<5 \%)$ presenting extreme patterns of scores. Consequently, the three-profile solution was retained.

The means of the predictors, and the intercepts of the outcomes in these profiles, are graphically presented in Figure 1. The exact values are reported in Table $\mathrm{S} 3$ of the online supplements. It is important to keep in mind that, because all of these variables are factor scores from preliminary measurement models estimated to have a mean of 0 and a standard deviation of 1 , these results can be interpreted in standard deviation units.

\section{Between-Profile Observations}

Profile 1 corresponds to $66 \%$ of the employees who reported being exposed to a moderately high level of transformational leadership coupled with a moderately low level of petty tyranny compared to other employees in the sample. As shown in Table S3, the mean differences between the levels of transformational leadership and petty tyranny observed in this profile correspond to roughly .5 SD and are associated with non-overlapping confidence intervals. We hereafter refer to this specific supervisory profile as Moderately Transformational. This profile presents the highest levels of transformational leadership and the lowest level of petty tyranny of all profiles. Employees exposed to such leaders present the highest levels on all outcomes.

Profile 2 corresponds to a smaller (6\%), but worrisome, subset of employees who report being exposed to very high levels of petty tyranny coupled with very low levels of transformational leadership. We refer to this specific supervisory profile as Destructive. This profile presents the most extreme levels of both types of leaderships observed in this study. Employees of such leaders display lower than average levels of thriving and empowered behaviors. However, with the exception of efficacy in performing their job tasks, these employees do not present the lowest levels on the other outcomes.

Profile 3 corresponds to $28 \%$ of the employees who reported being exposed to close to average levels of transformational leadership and petty tyranny (both levels are roughly .2 SD below the sample mean and display overlapping confidence intervals). We hereafter refer to this supervisory profile as Inconsistent, because this subset of employees is subjected to a supervisor that inconsistently relies on DLB or CLB, thus making it harder for these employees to anticipate their supervisors' behaviors in any specific situation. In fact, this profile displays the smallest difference between these two leadership behaviors (less than .05 SD of difference between levels of CLB and DLB, compared to close to .5 SD of difference in Profile 1). In addition, although levels of DLB and CLB taken on their own differ across profiles, the combined levels of both types of behaviors observed in this profile do not markedly differ 
from the combined levels of CLB and DLB observed in the other profiles, especially Profile 1 (also close to average when levels of CLB and DLB are aggregated). Thus, employees exposed to this type of supervisors present the lowest levels on all outcomes, excluding efficacy in performing job tasks.

In sum, the profiles appear to present mixtures of DLB and CLB, which take the form of small (Profile 1), very small (Profile 3), or quite pronounced (Profile 2) variations around the mean. In particular, the configurations observed in Profiles 1 and 3 answer RQ1 by supporting the idea that CLB and DLB can co-exist in some specific profiles of employees, whereas the configuration observed in Profile 2 also support the idea that some supervisors do indeed rely predominantly on one type of behavior. In addition, within-domain exacerbation seems to be observed as employees exposed to the Inconsistent profile display lower scores on almost all outcomes relative to the Destructive profile, thus supporting $H 1$ and $H 2$.

More specifically, employees from the Inconsistent profile seem to face more conflicting behaviors from supervisors that are neither clearly constructive, nor clearly destructive, but who tend to display both types of behaviors at a more similar level. As this profile was also found to display the least desirable outcome levels, it clearly appears to match the within-domain exacerbation. In contrast, employees corresponding to the Moderately Transformational profile also report being exposed to supervisors relying on some levels of both CLB and DLB. However, in this clearer profile, CLB levels were above average and close to .5 SD higher than below average DLB levels. This leadership profile does not appear carry any risk for exposed employees, who present the most desirable outcome levels.

\section{Within-Profile Observations}

The results from the within-profile regressions estimated in each of these profiles are reported in Table 4. In the context of hybrid mixture regression, these regressions provide an estimate of the residual associations between predictors and outcomes not explained at the between-profile level (i.e., the within-profile relations occurring above and beyond the between-profiles associations). For the Inconsistent profile, increases in either transformational leadership or petty tyranny scores appear to yield some benefits. More precisely, perceiving higher levels of transformational leadership is associated with higher levels of thriving at work, efficacy in performing job tasks, improvement efforts in job tasks, and effective collaboration in the workgroup for the employees. Likewise, within-profile increases in petty tyranny is associated with higher levels of effective collaboration in the workgroup, improvement efforts in the workgroup, and involvement at the organizational level. This last set of results is particularly interesting and suggests that any contribution to the clarification of a dominantly Inconsistent leadership style appears to be helpful for employees, thus providing further support to the logic of the uncertainty mechanism (RQ2). For the Moderately Transformational profile, an increase in transformational leadership is systematically related to additional increases on all outcomes, while increases in petty tyranny are not related to any outcome. More precisely, our results suggest that employees exposed to mostly transformational supervisors seem protected against the deleterious effects of these rare DLB. Finally, for the Destructive profile, within-profile increases in transformational leadership is associated with higher levels of thriving at work and involvement at the organization level, but lower levels in efficacy in performing job tasks. However, within-profile increases in petty tyranny is also related to higher levels of involvement at the organization level.

\section{Demographic Correlates}

The results regarding the demographics correlates of profile membership are reported in Table 1. These results support the idea that the nature of the profiles is mainly explained by the relations between the leadership behaviors and the outcomes rather than being an artefact of participants' demographic characteristics. However, some differences should be considered. Employees exposed to Moderately Transformational leaders tend to more frequently occupy supervisor roles. They also tend to work more hours than those exposed to Inconsistent leaders. Finally, employees exposed to Destructive leaders tend to have a longer tenure with their supervisors and in their position. They also tend to be older than employees exposed to Inconsistent leaders. Yet, in all of these cases, the observed differences remained small enough to be considered to have only a very limited amount of practical relevance.

\section{Discussion}

This study sought to understand how leaders combine DLB and CLB, here operationalized by transformational leadership and petty tyranny. It also sought to expand our understanding of the withindomain exacerbation phenomenon by examining how a leadership profile that jointly expose followers 
to DLB and CLB could be related to less desirable outcomes in terms of thriving at work and behavioral empowerment than exposure to a leadership profile dominated by DLB.

First, this study supports the proposition that leadership is not a dichotomous phenomenon and that most leaders rather seem to combine some levels of DLB and CLB. Second, results show that within-domain exacerbation could be elicited when employees are exposed to Inconsistent supervisors. These followers were those presenting the least desirable outcomes, even lower than those observed among employees exposed to purely Destructive supervisors. The sole exception was related to employees' efficacy in performing their job tasks. This suggests that a leader who is inconsistently a source of stress and support through his/her leadership behaviors could limit thriving and the willingness to go beyond job requirements, without necessarily affecting one's ability to meet the requirements of the job beyond the undesirable effects of exposure to DLB.

Incidentally, the shape of the profiles and the nature of the observed within-profile variations seem to suggest that the uncertainty mechanism could explain the within-domain exacerbation effect in this sample. First, the shape of the profiles suggests that employees exposed to Inconsistent supervisors appear to know that their leader can use both DLB and CLB, while having more difficulty anticipating which of these two types of behaviors they will rely across different types of situations, interactions, or contexts. Thus, exposure to these mixed and hard to predict messages coming from their supervisors might hinder employees' ability to understand what their goals are and how to achieve them in a way that will satisfy their supervisor, as well as their ability to come to terms with the exact nature of their relationship with their supervisor. Interestingly, as shown in the demographic comparisons, no difference was observed across profiles in relation to the frequency of contact between employees and their supervisor, suggesting that the lower outcome levels observed in the Inconsistent profile did not result from having a more absent leader. In contrast, followers of Moderately Transformational supervisors presented the most desirable outcome levels even though they might sometimes be exposed to DLB, although less frequently than followers of Inconsistent supervisors. This further suggests that within-domain exacerbation is probably not elicited by any combination of DLB and CLB, but rather observed only when employees have more difficulty to anticipate the specific nature of their supervisor's leadership.

Second, as predicted by the uncertainty management theory (van den Bos \& Lind, 2002) followers of Inconsistent leaders are more reactive to any clarification of their supervisors' leadership style, contrary to followers of supervisors presenting a clearer and more consistent leadership style. For employees exposed to a leader who is neither more clearly tyrannical nor transformational, increases in either CLB or DLB seemed to yield some benefits in terms of thriving and behavioral empowerment, suggesting that any contribution to resolve the strain and discomfort resulting from leadership inconsistency might be helpful to subordinates. For these followers, increases in transformational leadership seem to lead them to shift their focus toward the empowered behaviors related to the accomplishment of their work, while also increasing thriving. However, increases in petty tyranny seem to lead them to shift their focus toward behaviors more directed to their colleagues and outward involvement, maybe as a way to cope with DLB. Likewise, for followers of Destructive supervisors, increases in petty tyranny were also related to higher levels of involvement at the organizational level.

Additionally, in the Destructive profile, increases in transformational leadership were positively related to thriving and organizational involvement, but negatively related to efficacy in performing job tasks. These results suggest that increases in transformational leadership generally seem to lessen the strain caused by DLB, thus fostering thriving. However, increases in CLB from otherwise highly Destructive supervisors could be perceived as insincere attempts at manipulation (Barling et al., 2008), which could explain a desire to seek support outside of the work unit to the detriment of one's efficacy. Finally, variations in petty tyranny were not related to any outcome, suggesting a buffering effect of a leadership style dominated by CLB.

\section{Theoretical Contributions}

First, this study answers Einarsen et al. (2010) and Tepper et al. (2017) call for research for the investigation of possible combinations of DLB and CLB. Regarding combinations of petty tyranny and transformational leadership, supervisors appear to be either more clearly destructive, moderately more transformational than average, while not excluding the possibility of relying on petty tyranny, or showing close to average levels on both.

Second, this study offers theoretical insight on the leadership behaviors that may elicit within- 
domain exacerbation. Most previous studies examined within-domain exacerbation by looking at social support, at the quality of the supervisor-subordinate relationship, and at DLB. However, to our knowledge, no previous study has examined more specific forms of leadership practices such as transformational leadership. By finding evidence of within-domain exacerbation, our results suggest that this phenomenon is not behavior-dependent, but more likely message-dependent. This study also expands knowledge of the within-domain exacerbation effect by considering a distinct range of outcomes than what has been previously considered, and showed that the deleterious effect of combining DLB and CLB extends to work-related attitudes and behaviors, such as thriving and behavioral empowerment.

Furthermore, this study suggests that the uncertainty mechanism could underlie the withindomain exacerbation effect. When confronted with inconsistent leadership behaviors, followers may feel uncertainty as they lack the ability to anticipate and control their environment, their relationship with their supervisor, and their perception of themselves (Lind \& van den Bos, 2002; van den Bos \& Lind, 2002). This uncertainty could make it harder for them to devise efficient coping strategies (van Harreveld et al., 2015; Uchino et al., 2001). Our results show that seeking outward forms of involvement could represent a way to cope with exposure to higher levels of destructive leadership. This is consistent with the search for social support as a form of problem-focused coping strategy (Aquino \& Thau, 2009) and is coherent with previous studies showing outward social support could act as a buffer against the negative psychological and behavioral consequences of DLB (Duffy et al., 2002; Schat \& Kelloway, 2003). Interestingly, employees exposed to Inconsistent supervisors present the lowest levels on almost all behavioral empowerment dimensions. However, when petty tyranny is increased in this profile, employees seem to seek more involvement in both their workgroup and the organization. Similarly, employees exposed to more consistently Destructive supervisors show higher levels on these dimensions of behavioral empowerment. Additionally, as petty tyranny increases in this profile, employees mainly sought investment outside of their workgroup. Thus, a clearer destructive leadership style than the Inconsistent profile could be necessary to motivate employees to seek group and organizational involvement as a way of coping and possibly escaping their supervisor.

To be clear, this study does not suggest that the negative consequences of DLB on followers are any less important, or that in some situations, petty tyranny could be desirable as proposed by Ma et al. (2004). On the contrary, these results need to be interpreted while keeping in mind that employees exposed to Inconsistent or Destructive supervisors do tend to present lower than desirable levels on most outcomes.

\section{Limitations and Direction for Future Research}

Results should be interpreted with caution as some limitations need to be considered. First, this study relied on a cross-sectional data, which precludes any causal or directional interpretations. New studies should adopt longitudinal designs to better document the directional interplay between CLB and DLB. Second, this study relied on followers' reports of their supervisor's leadership behaviors and of their own levels of thriving and behavioral empowerment. It is worth mentioning that self-reports are considered to be a reliable approach when dealing with hard to observe behaviors (e.g., Vandenberg et al., 2004) such as thriving, and that multivariate person-centered analyses such as those used in the present study are known to be naturally protected against the effects of shared method variance (Meyer \& Morin, 2016; Siemsen et al., 2010). Yet, it would be interesting for future studies to consider relying on more objective external sources for the assessment of followers' behaviors, in order to reduce the social desirability of these ratings. Likewise, combining subordinate reports of their supervisors with more objective external ratings of leadership behaviors would be an interesting way to better disaggregate the objective and subjective underpinning of supervisors' impact on subordinates. Finally, laboratory studies (e.g., Towler, 2003) would make it possible to experimentally manipulate (via videos or role-playing exercises) the degree to which the co-occurrence of CLB and DLB can be considered to be, or not, inconsistent. As such, experimental studies would provide a way to further refine our understanding of the mechanisms underpinning the within-domain exacerbation phenomenon.

From a more theoretical perspective, although our results provide support to the plausibility of the uncertainty mechanism underpinning the within-domain exacerbation phenomenon, actual perceived uncertainty regarding the supervisor's leadership behaviors was not directly assessed. Thus, the mediating role of uncertainty between DLB and CLB combinations and work-related outcomes was not directly verified, but was rather theoretically inferred from our results. Future studies should incorporate 
such measures in order to more directly probe the cognitive underpinnings of this phenomenon. Additionally, it would be important to verify if these profiles can be replicated and if other profiles (e.g., Fully Transformational) would be observed in different industries and cultures. The absence of these other possible profiles is possibly linked to the fact that this study was conducted in a police organization where DLB are more commonly expected from leaders (Girodo, 1998; Vito et al., 2011). Finally, future studies would do well to investigate the extent to which the within-domain exacerbation phenomenon as well as the uncertainty mechanism would generalize, or not, to a wider variety of leadership behaviors. Practical Implications

From a practical standpoint, this study shows that the within-domain exacerbation phenomenon evoked by exposure to supervisors relying on an inconsistent combination of DLB and CLB could be a relatively frequent phenomenon (corresponding to $28 \%$ of the present sample). Exposure to such Inconsistent supervisors, as well as to Destructive supervisors, appears to be associated with a variety of important negative consequences for employees. What is most worrying is that these Inconsistent supervisors, who present a generally more nuanced leadership profile than their purely Destructive peers, may not be identified as a threat that is as salient as the one posed by Destructive supervisors, although they also appear to represent a clear human and financial burden for organizations. Therefore, we propose that organizations should orient their leadership related initiatives around three key principles. First, leaders should try to be as constructive as they can. Second, organizational initiatives should not only focus on CLB, but also on reducing DLB, and on the importance of achieving a clear leadership profile. Third, an Inconsistent leadership profile is disempowering and hinders followers' growth in an organization. These principles could be conveyed to supervisors through leadership training programs encompassing both CLB and DLB (Hogan et al., 2011), but also through values statement and awareness campaigns. Comprehensive measures of leadership, including both CLB and DLB, should also be used to increase leaders' awareness of their leadership profile, and supervisors with problematic profiles should have access to support (i.e., coaching or training) to help them avoid inconsistency or destructiveness. Additionally, as more and more organizations use weekly and monthly survey platforms, these communication tools could be used to offer quick corrective feedback to supervisors about their behaviors.

\section{References}

Aasland, M. S., Skogstad, A., Notelaers, G., Nielsen, M. B., \& Einarsen, S. (2010). The prevalence of destructive leadership behaviour. British Journal of Management, 21(2), 438-452.

Aquino, K. \& Thau, S. (2009). Workplace victimization: Aggression from the target's perspective. Annual Review of Psychology, 60(1), 717-741.

Aryee, S., Sun, L.-Y., Chen, Z. X. G., \& Debrah, Y. A. (2008). Abusive supervision and contextual performance: The mediating role of emotional exhaustion and the moderating role of work unit structure. Management and Organization Review, 4(03), 393-411.

Ashforth, B. E. (1994). Petty tyranny in organizations. Human Relations, 47(7), 755-778.

Ashforth, B. E. (1997). Petty tyranny in organizations: A preliminary examination of antecedents and consequences. Canadian Journal of Administrative Sciences / Revue Canadienne Des Sciences de l'Administration, 14(2), 126-140.

Asparouhov, T. (2005). Sampling weights in latent variable modeling. Structural Equation Modeling, $12(3), 411-434$.

Asparouhov, T. \& Muthén, B. O. (2007). Wald test of mean equality for potential latent class predictors in mixture modeling. http://www.statmodel.com/download/MeanTestl. pdf.

Avolio, B. J. \& Bass, B. M. (2004). Multifactor leadership questionnaire - Manual \& sampler set $\left(3^{\text {rd }}\right.$ ed.). Palo Alto, CA: Mind Garden Inc.

Barling, J., Christie, A., \& Turner, N. (2008). Pseudo-transformational leadership: Towards the development and test of a model. Journal of Business Ethics, 81(4), 851-861.

Bass, B. M. \& Bass, R. (2008). The Bass handbook of leadership: Theory, research, and management applications $\left(4^{\text {th }}\right.$ ed.). Free Press.

Bass, B. M. \& Riggio, R. E. (2006). Transformational leadership ( $2^{\text {nd }}$ ed.). Lawrence Erlbaum Associates.

Bauer, D. J. (2005). A semiparametric approach to modeling nonlinear relations among latent variables. Structural Equation Modeling, 12(4), 513-535.

Baumeister, R. F., Gailliot, M., DeWall, C. N., \& Oaten, M. (2006). Self-regulation and personality: 
How interventions increase regulatory success, and how depletion moderates the effects of traits on behavior. Journal of Personality, 74(6), 1773-1802.

Bono, J. E., \& Judge, T. A. (2004). Personality and transformational and transactional leadership: a meta-analysis. Journal of Applied Psychology, 89(5), 901.

Boudrias, J.-S., Brunelle, É., Chénard Poirier, L.-A., Rousseau, V., Phaneuf, J.-É., \& Lajoie, D. (2015). Quels sont les facteurs liés à l'émergence du leadership transformationnel? Résultats d'une étude empirique [What are the factors associated with the emergence of transformational leadership? Results of an empirical study]. Humain et Organisation, 1(1), 1-6.

Boudrias, J.-S, Gaudreau, P., Savoie, A., \& Morin, A. J. S. (2009). Employee empowerment: From managerial practices to employees' behavioral empowerment. Leadership \& Organization Development Journal, 30(7), 625-638.

Boudrias, J.-S., Morin, A. J. S., \& Lajoie, D. (2014). Directionality of the associations between psychological empowerment and behavioural involvement: A longitudinal autoregressive crosslagged analysis. Journal of Occupational and Organizational Psychology, 87(3), 437-463.

Boudrias, J.-S., Rousseau, V., Aubé, C., Savoie, A., Duguay, G., \& Morin, E. M. (2010). L'habilitation comportementale au travail: Structure factorielle et convergence/ distinction avec l'habilitation psychologique. Revue Québécoise de Psychologie, 31(2), 173-199.

Breevaart, K., \& Bakker, A. B. (2014). The influence of constructive and destructive leadership behaviors on follower burnout. In M. Leiter, A. Bakker, \& C. Maslach (Eds.), Burnout at Work (p. 110-129). Psychology Press.

Byrne, A., Dionisi, A. M., Barling, J., Akers, A., Robertson, J., Lys, R., Wylie, J., \& Dupré, K. (2014). The depleted leader: The influence of leaders' diminished psychological resources on leadership behaviors. The Leadership Quarterly, 25(2), 344-357.

Cacciatore, G. (2015). Petty tyranny as a form of destructive leadership: Results of studies based on a French-Canadian measure [Doctoral dissertation]. Université du Québec à Montréal.

Cacciatore, G., Morin, D., Nelson, K., \& Boudrias, J.-S. (2010). Le leadership tyrannique: Définition et validation d'une mesure mesure [Tyrannical leadership: Definition and validation of a measure]. Proceedings of the $16^{\text {th }}$ Congress of the Association Internationale de Psychologie du Travail de Langue Française.

Chan, M. E. \& McAllister, D. J. (2014). Abusive supervision through the lens of employee state paranoia. Academy of Management Review, 39(1), 44-66.

Chénard-Poirier, L. A., Morin, A. J. S. \& Boudrias, J.-S. (2017). On the merits of coherent leadership empowerment behaviors: A mixture regression approach. Journal of Vocational Behavior, 103, 66-75.

Collins, M. D., \& Jackson, C. J. (2015). A process model of self-regulation and leadership: How attentional resource capacity and negative emotions influence constructive and destructive leadership. The Leadership Quarterly, 26(3), 386-401.

Cropanzano, R., Anthony, E. L., Daniels, S. R., \& Hall, A. V. (2017). Social exchange theory: A critical review with theoretical remedies. Academy of Management Annals, 11(1), 479-516.

De Cremer, D. (2003). Why inconsistent leadership is regarded as procedurally unfair: the importance of social self-esteem concerns. European Journal of Social Psychology, 33(4), 535-550.

Duffy, M. K., Ganster, D. C., \& Pagon, M. (2002). Social undermining in the workplace. Academy of Management Journal, 45(2), 331-351.

Edwards, J. R. (2009). Latent variable modeling in congruence research: Current problems and future directions. Organizational Research Methods, 12(1), 34-62.

Einarsen, S., Aasland, M. S., \& Skogstad, A. (2010). The nature and outcomes of destructive leadership behavior in organizations. In R. J. Burke \& C. L. Cooper (Eds.), Risky business: psychological, physical, and financial costs of high risk behavior in organizations (p. 323-349). Gower Publishing.

Eissa, G., \& Lester, S. W. (2017). Supervisor role overload and frustration as antecedents of abusive supervision: The moderating role of supervisor personality. Journal of Organizational Behavior, $38(3), 307-326$.

Enders, C. K. (2010). Applied missing data analysis. Guilford Press.

Frieder, R. E., Hochwarter, W. A., \& DeOrtentiis, P. S. (2015). Attenuating the negative effects of abusive supervision: The role of proactive voice behavior and resource management ability. The 
Leadership Quarterly, 26(5), 821-837.

Furtner, M. R., Maran, T., \& Rauthmann, J. F. (2017). Dark leadership: The role of leaders' dark triad personality traits. In M. G. Clark et C. W. Gruber (Eds.), Leader development deconstructed (p. 75-99). Springer International Publishing.

Gillet, N., Morin, A. J. S., Sandrin, E., \& Houle, S. A. (2018). Investigating the combined effects of workaholism and work engagement: A substantive-methodological synergy of variable-centered and person-centered methodologies. Journal of Vocational Behavior, 109(2018), 54-77.

Girodo, M. (1998). Machiavellian, bureaucratic, and transformational leadership styles in police managers: Preliminary findings of interpersonal ethics. Perceptual and Motor Skills, 86(2), 419-427.

Harms, P. D., \& Credé, M. (2010). Emotional intelligence and transformational and transactional leadership: A meta-analysis. Journal of Leadership \& Organizational Studies, 17(1), 5-17.

Harvey, P., Stoner, J., Hochwarter, W., \& Kacmar, C. (2007). Coping with abusive supervision: The neutralizing effects of ingratiation and positive affect on negative employee outcomes. The Leadership Quarterly, 18(3), 264-280.

Herr, R. M., van Harreveld, F., Uchino, B. N., Birmingham, W. C., Loerbroks, A., Fischer, J. E., \& Bosch, J. A. (2018). Associations of ambivalent leadership with distress and cortisol secretion. Journal of Behavioral Medicine, 42(2), 265-275.

Hildenbrand, K., Sacramento, C. A., \& Binnewies, C. (2018). Transformational leadership and burnout: The role of thriving and followers' openness to experience. Journal of Occupational Health Psychology, 23(1), 31-43.

Hipp, J. R. \& Bauer, D. J. (2006). Local solutions in the estimation of growth mixture models. Psychological Methods, 11(1), 36-53.

Hobman, E. V., Restubog, S. L. D., Bordia, P., \& Tang, R. L. (2009). Abusive supervision in advising relationships: Investigating the role of social support. Applied Psychology, 58(2), 233-256.

Hoch, J. E., Bommer, W. H., Dulebohn, J. H., \& Wu, D. (2018). Do ethical, authentic, and servant leadership explain variance above and beyond transformational leadership? A meta-analysis. Journal of Management, 44(2), 501-529.

Hogan, J., Hogan, R., \& Kaiser, R. B. (2011). Management derailment. In S. Zedeck (Ed.), APA handbook of industrial and organizational psychology (vol. 3, p. 555-575). American Psychological Association.

Holt-Lunstad, J., Uchino, B. N., Smith, T. W., Olson-Cerny, C., \& Nealey-Moore, J. B. (2003). Social relationships and ambulatory blood pressure: structural and qualitative predictors of cardiovascular function during everyday social interactions. Health Psychology, 22(4), 388.

Hu, L. \& Bentler, P. M. (1999). Cutoff criteria for fit indexes in covariance structure analysis: Conventional criteria versus new alternatives. Structural Equation Modeling, 6(1), 1-55.

Hu, L., \& Liu, Y. (2017). Abuse for status: A social dominance perspective of abusive supervision. Human Resource Management Review, 27(2), 328-337.

Kiazad, K., Restubog, S. L. D., Zagenczyk, T. J., Kiewitz, C., \& Tang, R. L. (2010). In pursuit of power: The role of authoritarian leadership in the relationship between supervisors' Machiavellianism and subordinates' perceptions of abusive supervisory behavior. Journal of Research in Personality, 44(4), 512-519.

Kim, M., Beehr, T. A., \& Prewett, M. S. (2018). Employee responses to empowering leadership. Journal of Leadership \& Organizational Studies, 25(3), 257-276.

Krasikova, D. V., Green, S. G., \& LeBreton, J. M. (2013). Destructive leadership: A theoretical review, integration, and future research agenda. Journal of Management, 39(5), 1308-1338.

Lajoie, D., Boudrias, J.-S., Rousseau, V., \& Brunelle, É. (2017). Value congruence and tenure as moderators of transformational leadership effects. Leadership \& Organization Development Journal, 38(2), 254-269.

Lian, H., Ferris, D. L., \& Brown, D. J. (2012). Does taking the good with the bad make things worse? How abusive supervision and leader-member exchange interact to impact need satisfaction and organizational deviance. Organizational Behavior and Human Decision Processes, 117(1), 41-52.

Lind, E. A. \& van den Bos, K. (2002). When fairness works: Toward a general theory of uncertainty management. Research in Organizational Behavior, 24(2002), 181-223. 
Lo, Y., Mendell, N. R., \& Rubin, D. B. (2001). Testing the number of components in a normal mixture. Biometrika, 88(3), 767-778.

Lyu, D., Ji, L., Zheng, Q., Yu, B., \& Fan, Y. (2019). Abusive supervision and turnover intention: Mediating effects of psychological empowerment of nurses. International Journal of Nursing Sciences, 6(2), 198-203.

Ma, H., Karri, R., \& Chittipeddi, K. (2004). The paradox of managerial tyranny. Business Horizons, 47(4), 33-40.

Mackey, J. D., Frieder, R. E., Brees, J. R., \& Martinko, M. J. (2017). Abusive supervision: A metaanalysis and empirical review. Journal of Management, 43(6), 1940-1965.

Major, B. \& Zubek, J. M. (1997). Mixed messages: Implications of social conflict and social support within close relationships for adjustment to a stressful life event. Journal of Personality and Social Psychology, 72(6), 1349-1363.

Marsh, H. W., Hau, K.-T., \& Grayson, D. (2005). Goodness of fit evaluation in structural equation modeling. In A. Maydeu-Olivares \& J. McArdle (Eds.), Multivariate applications book series. Contemporary psychometrics: A festschrift for Roderick P. McDonald (p. 275-340). Lawrence Erlbaum Associates Publishers.

Marsh, H. W., Lüdtke, O., Trautwein, U., \& Morin, A. J. S. (2009). Classical latent profile analysis of academic self-concept dimensions: Synergy of person- and variable-centered approaches to theoretical models of self-concept. Structural Equation Modeling, 16(2), 191-225.

Marsh, H. W. \& O'Mara, A. J. (2010). Long-term total negative effects of school-average ability on diverse educational outcomes. Zeitschrift für Pädagogische Psychologie, 24(1), 51-72.

Mathieu, C. \& Babiak, P. (2016). Corporate psychopathy and abusive supervision: Their influence on employees' job satisfaction and turnover intentions. Personality and Individual Differences, 91(2016), 102-106.

Matta, F. K., Scott, B. A., Colquitt, J. A., Koopman, J., \& Passantino, L. G. (2017). Is consistently unfair better than sporadically fair? An investigation of justice variability and stress. Academy of Management Journal, 60(2), 743-770.

Mawritz, M. B., Folger, R., \& Latham, G. P. (2014). Supervisors' exceedingly difficult goals and abusive supervision: The mediating effects of hindrance stress, anger, and anxiety. Journal of Organizational Behavior, 35(3), 358-372.

McDonald, R. P. (1970). Theoretical foundations of principal factor analysis and alpha factor analysis. British Journal of Mathematical and Statistical Psychology, 23(1), 1-21.

Meyer, J. P. \& Morin, A. J. S. (2016). A person-centered approach to commitment research: Theory, research, and methodology. Journal of Organizational Behavior, 37(4), 584-612.

Morin, A. J. S. (2016). Person-centered research strategies in commitment research. In J.P. Meyer (Ed.), Handbook of employee commitment (p. 490-508). Edward Elgar.

Morin, A. J. S., Maïano, C., Nagengast, B., Marsh, H. W., Morizot, J., \& Janosz, M. (2011). General growth mixture analysis of adolescents' developmental trajectories of anxiety: The impact of untested invariance assumptions on substantive interpretations. Structural Equation Modeling, 18(4), 613-648.

Morin, A. J. S. \& Wang, J. C. K. (2016). A gentle introduction to mixture modeling using physical fitness performance data. In N. Ntoumanis \& N. Myers (Eds.), An introduction to intermediate and advanced statistical analyses for sport and exercise scientists (p. 183-210). Wiley.

Mullen, J., Kelloway, E. K., \& Teed, M. (2011). Inconsistent style of leadership as a predictor of safety behaviour. Work \& Stress, 25(1), 41-54.

Muthén, B. (2002). Beyond SEM: General latent variable modeling. Behaviormetrika, 29(1), 81-117.

Muthén, L. K. \& Muthén, B. (2015). Mplus User's Guide. Muthén \& Muthén.

Nahum-Shani, I., Henderson, M. M., Lim, S., \& Vinokur, A. D. (2014). Supervisor support: Does supervisor support buffer or exacerbate the adverse effects of supervisor undermining? Journal of Applied Psychology, 99(3), 484-503.

Niessen, C., Mäder, I., Stride, C., \& Jimmieson, N. L. (2017). Thriving when exhausted: The role of perceived transformational leadership. Journal of Vocational Behavior, 103(2017), 41-51.

Olsen, O. K., Pallesen, S., Torsheim, T., \& Espevik, R. (2016). The effect of sleep deprivation on leadership behaviour in military officers: An experimental study. Journal of Sleep Research, 25(6), 683-689. 
Pigeon, M., Montani, F., \& Boudrias, J.-S. (2017). How do empowering conditions lead to empowered behaviours? Test of a mediation model. Journal of Managerial Psychology, 32(5), 357-372.

Porath, C., Spreitzer, G., Gibson, C., \& Garnett, F. G. (2011). Thriving at work: Toward its measurement, construct validation, and theoretical refinement. Journal of Organizational Behavior, 33(2), 250-275.

Proudfoot, D. \& Lind, E. A. (2015). Fairness heuristic theory, the uncertainty management model, and fairness at work. In R. S. Cropanzano \& M. L. Ambrose (Eds.), The Oxford handbook of justice in the workplace (p. 371-385). Oxford University.

Rayner, C. \& Cooper, C. L. (2003). The black hole in «"bullying at work" » research. International Journal of Management and Decision Making, 4(1), 47-64.

Restubog, S. L. D., Scott, K. L., \& Zagenczyk, T. J. (2011). When distress hits home: The role of contextual factors and psychological distress in predicting employees' responses to abusive supervision. Journal of Applied Psychology, 96(4), 713-729.

Rozin, P., \& Royzman, E. B. (2001). Negativity bias, negativity dominance, and contagion. Personality and Social Psychology Review, 5(4), 296-320.

Schat, A. C. H. \& Kelloway, E. K. (2003). Reducing the adverse consequences of workplace aggression and violence: The buffering effects of organizational support. Journal of Occupational Health Psychology, 8(2), 110-122.

Schriesheim, C. A., House, R. J., \& Kerr, S. (1976). Leader initiating structure: A reconciliation of discrepant research results and some empirical tests. Organizational Behavior and Human Performance, 15(2), 297-321.

Schyns, B. \& Schilling, J. (2013). How bad are the effects of bad leaders? A meta-analysis of destructive leadership and its outcomes. The Leadership Quarterly, 24(1), 138-158.

Seibert, S. E., Wang, G., \& Courtright, S. H. (2011). Antecedents and consequences of psychological and team empowerment in organizations: A meta-analytic review. Journal of Applied Psychology, 96(5), 981-1003.

Siemsen, E., Roth, A., \& Oliveira, P. (2010). Common method bias in regression models with linear, quadratic, and interaction effects. Organizational Research Methods, 13(3), 456-476.

Skrondal, A. \& Laake, P. (2001). Regression among factor scores. Psychometrika, 66(4), 563-575.

Sonnentag, S., \& Frese, M. (2003). Stress in organizations. In W. C. Borman, D. R. Ilgen, R. J. Klimoski (Eds.), Comprehensive handbook of psychology (vol. 12: Industrial and organizational psychology, p. 453-491). John Wiley \& Sons, Inc.

Sparks, K., Faragher, B., \& Cooper, C. L. (2001). Well-being and occupational health in the 21 st century workplace. Journal of Occupational and Organizational Psychology, 74(4), 489-509.

Spreitzer, G. (2008). Taking Stock: A review of more than twenty years of research on empowerment at work. In J. Barling \& C. L. Cooper (Eds.), Handbook of organizational behavior (vol. 1, p. 54-72). Sage.

Spreitzer, G., Sutcliffe, K., Dutton, J., Sonenshein, S., \& Grant, A. M. (2005). A socially embedded model of thriving at work. Organization Science, 16(5), 537-549.

Swann, W. B., Jr., Rentfrow, P. J., \& Guinn, J. S. (2003). Self-verification: The search for coherence. In M. R. Leary \& J. P. Tangney (Eds.), Handbook of self and identity (p. 367-383). Guilford Press.

Tan, H.-T. \& Lipe, M. G. (1997). Outcome effects: The impact of decision process and outcome controllability. Journal of Behavioral Decision Making, 10(4), 315-325.

Tepper, B. J. (2000). Consequences of abusive supervision. Academy of Management Journal, 43(2), 178-190.

Tepper, B. J. (2007). Abusive supervision in work organizations: Review, synthesis, and research agenda. Journal of Management, 33(3), 261-289.

Tepper, B. J., Simon, L., \& Park, H. M. (2017). Abusive supervision. Annual Review of Organizational Psychology and Organizational Behavior, 4(2017), 123-152.

Towler, A.J. (2003). Effects of charismatic influence training on attitudes, behavior, and performance. Personnel Psychology, 56(2), 363-381.

Uchino, B. N., Holt-Lunstad, J., Uno, D., \& Flinders, J. B. (2001). Heterogeneity in the social networks of young and older adults: Prediction of mental health and cardiovascular reactivity during acute stress. Journal of Behavioral Medicine, 24(4), 361-382. 
van den Bos, K. et Lind, E. A. (2002). Uncertainty management by means of fairness judgments. Experimental Social Psychology, 34(2002), 1-60.

van Harreveld, F., Nohlen, H. U., \& Schneider, I. K. (2015). The ABC of ambivalence: Affective, behavioral, and cognitive consequences of attitudinal conflict. Advances in Experimental Social Psychology, 52(2015), 285-324.

Van Horn, M. L., Jaki, T., Masyn, K., Ramey, S. L., Smith, J. A., \& Antaramian, S. (2009). Assessing differential effects: Applying regression mixture models to identify variations in the influence of family resources on academic achievement. Developmental Psychology, 45(5), 1298-1313.

Vandenberg, R.J., Lance, C.E., \& Taylor, S.C. (2004). A latent variable approach to rating source equivalence: Who should provide ratings on organizational citizenship behavior dimensions? In D.L. Turnipseed (Ed.), A handbook of organizational citizenship behavior (p. 105-138). Nova Science.

Vito, G. F., Suresh, G., \& Richards. (2011). Emphasizing the servant in public service: The opinions of police managers. Policing: An International Journal of Police Strategies and Management, 34(4), 674-686.

Vogel, R. M., \& Mitchell, M. S. (2017). The motivational effects of diminished self-esteem for employees who experience abusive supervision. Journal of Management, 43(7), 2218-2251.

Wang, H., Law, K. S., Wang, D., \& Chen, Z. X. (2005). Leader-member exchange as a mediator of the relationship between transformational leadership and followers' performance and organizational citizenship behavior. Academy of Management Journal, 48(3), 420-432.

Wang, W., Oh, I.-S., Courtright, S. H., \& Colbert, A. E. (2011). Transformational leadership and performance across criteria and levels: A meta-analytic review of 25 years of research. Group \& Organization Management, 36(2), 223-270.

Wang, M., Sinclair, R., \& Deese, M. N. (2010). Understanding the causes of destructive leadership behavior: A dual-process model. In B. Schyns \& T. Hansbrough (Eds.), When leadership goes wrong: Destructive leadership, mistakes, and ethical failures (p. 73-97). IAP Information Age Publishing

Xu, A. J., Loi, R., \& Lam, L. W. (2015). The bad boss takes it all: How abusive supervision and leadermember exchange interact to influence employee silence. The Leadership Quarterly, 26(5), 763-774.

Zhang, Y., \& Bednall, T. C. (2016). Antecedents of abusive supervision: A meta-analytic review. Journal of Business Ethics, 139(3), 455-471. 


\section{Tables and Figures}

Table 1

Demographic Characteristics of the Sample and Profiles

\begin{tabular}{|c|c|c|c|c|c|}
\hline & Full Sample & $\begin{array}{c}\text { Profile } 1 \\
(66 \%)\end{array}$ & $\begin{array}{c}\text { Profile } 2 \\
(6 \%)\end{array}$ & $\begin{array}{c}\text { Profile } 3 \\
(28 \%)\end{array}$ & \\
\hline & \multicolumn{4}{|c|}{ Frequency $(\%)$} & Significance tests \\
\hline \multicolumn{6}{|l|}{ Sex } \\
\hline Male & 61.3 & 61.9 & 60.3 & 60.2 & \multirow{2}{*}{$1=2=3$} \\
\hline Female & 38.7 & 38.1 & 39.7 & 39.8 & \\
\hline \multicolumn{6}{|l|}{ Age } \\
\hline Less than 19 & 0 & 0 & 0 & 0 & \multirow{6}{*}{$1=2 ; 1=3 ; 2>3$} \\
\hline Between 20 and 29 & 18.2 & 17.8 & 15.1 & 19.6 & \\
\hline Between 30 and 39 & 34.9 & 34.8 & 31.0 & 35.9 & \\
\hline Between 40 and 49 & 34.6 & 35.8 & 34.1 & 31.9 & \\
\hline Between 50 and 59 & 11.6 & 10.8 & 17.5 & 12.1 & \\
\hline 60 or more & 0.7 & 0.7 & 2.4 & 0.5 & \\
\hline \multicolumn{6}{|l|}{ Education } \\
\hline High School diploma or less & 3.5 & 2.9 & 3.9 & 4.7 & \multirow{7}{*}{$1=2=3$} \\
\hline Professional diploma & 3.9 & 3.7 & 4.7 & 4.4 & \\
\hline College diploma (CEGEP) & 51.8 & 52.3 & 44.1 & 52.3 & \\
\hline University Major or Minor & 20.7 & 21.8 & 18.9 & 18.5 & \\
\hline Bachelor's degree & 15.1 & 14.2 & 20.5 & 15.9 & \\
\hline Post graduate certificate & 1.4 & 1.4 & 0.8 & 1.6 & \\
\hline Master or PhD degree & 3.6 & 3.6 & 7.1 & 2.6 & \\
\hline \multicolumn{6}{|l|}{ Supervisor } \\
\hline No & 82.5 & 79.3 & 87.1 & 89.4 & \multirow{2}{*}{$1>2=3$} \\
\hline Yes & 17.5 & 20.7 & 12.9 & 10.6 & \\
\hline \multicolumn{6}{|l|}{ Tenure in the position } \\
\hline Less than 6 months & 2.6 & 2.9 & 0 & 2.3 & \multirow{7}{*}{$2>1=3$} \\
\hline Between 6 and 11 months & 5.1 & 5.1 & 1.6 & 5.6 & \\
\hline Between 1 and 2 years & 7.9 & 8.2 & 9.4 & 7.1 & \\
\hline Between 3 and 5 years & 22.6 & 23.4 & 18.1 & 21.7 & \\
\hline Between 6 and 10 years & 26.3 & 26.1 & 27.6 & 26.6 & \\
\hline Between 11 and 15 years & 17.9 & 17.4 & 19.7 & 18.7 & \\
\hline More than 15 years & 17.6 & 16.9 & 23.6 & 18.0 & \\
\hline \multicolumn{6}{|l|}{ Contacts with the supervisor } \\
\hline More than one per day & 57.0 & 56.8 & 48.8 & 59.3 & \multirow{7}{*}{$1=2=3$} \\
\hline Once a day & 13.8 & 13.8 & 16.5 & 13.1 & \\
\hline Few times per week & 18.1 & 19.1 & 18.1 & 15.6 & \\
\hline Once a week & 5.5 & 5.2 & 7.1 & 6.1 & \\
\hline Two or three times per month & 3.7 & 3.5 & 4.7 & 3.8 & \\
\hline Once a month & 1.0 & 0.7 & 3.9 & 1.0 & \\
\hline \multirow[t]{2}{*}{ Few times per year } & 1.0 & 0.9 & 0.8 & 1.0 & \\
\hline & \multicolumn{3}{|c|}{$M(S D)$} & \multicolumn{2}{|r|}{ Significance tests } \\
\hline Organizational tenure (years) & $13.3(8.4)$ & $13.6(8.4)$ & $13.8(8.2)$ & $12.6(8.6)$ & $1=2=3$ \\
\hline Tenure with supervisor (years) & $2.0(2.4)$ & $2.0(2.3)$ & $2.8(3.1)$ & $1.9(2.2)$ & $2>1=3$ \\
\hline Hours worked per week & $35.6(6.0)$ & $35.8(6.1)$ & $35.0(6.2)$ & $35.3(5.8)$ & $1>3 ; 1=2 ; 2=3$ \\
\hline
\end{tabular}

Note. $M=$ Mean; All significance tests were conducted using a Wald-test of significance based on pseudoclass draws, significant differences indicated by greater than symbols are at $p<.05 ; N=2104$. 
Table 2

Latent Variable Correlations from The Preliminary Measurement Model

\begin{tabular}{lcccccccc}
\hline & 1. & 2. & 3. & 4. & 5. & 6. & 7. & 8. \\
\hline 1. Transformational leadership &. $\mathbf{9 7}$ & & & & & & & \\
2. Petty tyranny & $-.59^{*}$ &. $\mathbf{9 6}$ & & & & & & \\
3. Thriving at work & $.36^{*}$ & $-.19^{*}$ & $\mathbf{. 9 2}$ & & & & & \\
4. Efficacy in performing job tasks & $.19^{*}$ & $-.10^{*}$ & $.33^{*}$ & $\mathbf{. 8 9}$ & & & & \\
5. Improvement efforts in job tasks & $.25^{*}$ & $-.09^{*}$ & $.44^{*}$ & $.57^{*}$ & $\mathbf{. 9 0}$ & & & \\
6. Collaboration in the workgroup & $.26^{*}$ & -.04 & $.41^{*}$ & $.46^{*}$ & $.59^{*}$ & $\mathbf{. 7 9}$ & & \\
7. Improvement efforts in the workgroup & $.17^{*}$ & .01 & $.28^{*}$ & $.22^{*}$ & $.50^{*}$ & $.67^{*}$ & $\mathbf{. 8 7}$ & \\
8. Involvement at the organizational level & $.14^{*}$ & .02 & $.26^{*}$ & $.20^{*}$ & $.38^{*}$ & $.49^{*}$ & $.66^{*}$ & $\mathbf{. 8 9}$ \\
\hline
\end{tabular}

Note. Composite reliability coefficients are reported in bold in the diagonal and calculated

from the standardized parameter estimates, using McDonald's (1970) omega coefficient:

$\omega=(\Sigma|\lambda \mathrm{i}|)^{2} /\left([\Sigma|\lambda \mathrm{i}|]^{2}+\Sigma \delta \mathrm{ii}\right)$ where $\lambda \mathrm{i}$ are the factor loadings and $\delta$ ii, the error variances.

$* p<.05$. 
Table 3

Mixture Regression Models

\begin{tabular}{lccccccccc}
\hline \multicolumn{1}{c}{ Model } & LL & FP & Scaling & AIC & CAIC & BIC & ABIC & Entropy & aLMR \\
\hline 1 Class & -19002.83 & 44 & 1.86 & 38093.66 & 38386.33 & 38342.33 & 38202.54 & Na & Na \\
2 Class & -17898.14 & 71 & 1.55 & 35938.28 & 36410.54 & 36339.54 & 36113.97 & .78 & $<.01$ \\
3 Class & -17139.56 & 98 & 1.54 & 34475.12 & 35126.98 & 35028.98 & 34717.62 & .86 & $<.01$ \\
4 Class & -16701.33 & 125 & 1.43 & 33652.65 & 34484.10 & 34359.10 & 33961.97 & .89 & $<.01$ \\
5 Class & -16400.61 & 152 & 1.38 & 33105.22 & 34116.26 & 33964.26 & 33481.34 & .82 & $<.01$ \\
6 Class & -16176.71 & 179 & 1.45 & 32711.41 & 33902.05 & 33723.05 & 33154.35 & .84 & $>.05$ \\
7 Class & -15957.76 & 206 & 1.33 & 32327.53 & 33697.76 & 33491.76 & 32837.27 & .84 & $>.05$ \\
8 Class & -15800.02 & 233 & 1.35 & 32066.04 & 33615.86 & 33382.86 & 32642.60 & .84 & $>.05$ \\
\hline
\end{tabular}

Note . Scaling = scaling factor associated with MLR loglikelihood estimates; AIC: Akaïke Information Criteria; CAIC: Constant AIC; BIC:

Bayesian Information Criteria; ABIC: Sample-size Adjusted BIC; aLMR: Adjusted Lo-Mendell-Rubin likelihood ratio test. 
Table 4

Relations Between Intra-Profile Variations in Leadership Behaviors and Outcome Levels

\begin{tabular}{|c|c|c|c|c|c|c|c|c|c|c|c|c|}
\hline \multirow[b]{2}{*}{ Predictor } & \multicolumn{2}{|c|}{ Thriving at work } & \multicolumn{2}{|c|}{$\begin{array}{c}\text { Efficacy in } \\
\text { performing job } \\
\text { tasks }\end{array}$} & \multicolumn{2}{|c|}{$\begin{array}{c}\text { Improvement } \\
\text { efforts in job tasks }\end{array}$} & \multicolumn{2}{|c|}{$\begin{array}{l}\text { Collaboration in } \\
\text { the workgroup }\end{array}$} & \multicolumn{2}{|c|}{$\begin{array}{l}\text { Improvement } \\
\text { efforts in the } \\
\text { workgroup }\end{array}$} & \multicolumn{2}{|c|}{$\begin{array}{c}\text { Involvement at } \\
\text { the } \\
\text { organizational } \\
\text { level }\end{array}$} \\
\hline & $b(S E)$ & $\beta$ & $b(S E)$ & $\beta$ & $b(S E)$ & $\beta$ & $b(S E)$ & $\beta$ & $b(S E)$ & $\beta$ & $b(S E)$ & $\beta$ \\
\hline \multicolumn{13}{|l|}{ Profile $1(66 \%)$} \\
\hline Transformational leadership & $0.34 *(0.04)$ & .37 & $0.20 *(0.04)$ & .20 & $0.19 *(0.03)$ & .26 & $0.24 *(0.03)$ & .32 & $0.14 *(0.03)$ & .19 & $0.15 *(0.05)$ & .15 \\
\hline Petty tyranny & $-0.04(0.07)$ & -.03 & $-0.16(0.09)$ & -.10 & $-0.09(0.06)$ & -.07 & $-0.03(0.06)$ & -.03 & $0.03(0.06)$ & .03 & $0.07(0.09)$ & .04 \\
\hline $\mathrm{R}^{2}$ & .15 & & .07 & & .09 & & .11 & & .03 & & .02 & \\
\hline \multicolumn{13}{|l|}{ Profile $2(6 \%)$} \\
\hline Transformational leadership & $0.31 *(0.12)$ & .23 & $-0.19 *(0.09)$ & -.17 & $-0.04(0.09)$ & -.04 & $0.04(0.08)$ & .05 & $0.08(0.08)$ & .09 & $0.16 *(0.08)$ & .16 \\
\hline Petty tyranny & $0.06(0.12)$ & .03 & $0.00(0.09)$ & .00 & $0.13(0.08)$ & .09 & $0.07(0.08)$ & .05 & $0.13(0.08)$ & .09 & $0.20 *(0.08)$ & .13 \\
\hline $\mathrm{R}^{2}$ & .05 & & .03 & & .01 & & .00 & & .01 & & .02 & \\
\hline \multicolumn{13}{|l|}{ Profile $3(28 \%)$} \\
\hline Transformational leadership & $0.34 *(0.08)$ & .29 & $0.23 *(0.08)$ & .18 & $0.26 *(0.11)$ & .20 & $0.34 *(0.10)$ & .31 & $0.09(0.07)$ & .09 & $0.08(0.05)$ & .08 \\
\hline Petty tyranny & $0.04(0.09)$ & .02 & $0.11(0.12)$ & .06 & $-0.00(0.14)$ & .00 & $0.28 *(0.11)$ & .16 & $0.30 *(0.11)$ & .19 & $0.24 *(0.12)$ & .15 \\
\hline $\mathrm{R}^{2}$ & .08 & & .03 & & .04 & & .07 & & .03 & & .02 & \\
\hline
\end{tabular}

Note. $b$ : unstandardized coefficient; SE: standard error; $\beta$ : standardized coefficient; Variables are factor scores estimated in standardized units

$$
\begin{aligned}
& (M=0 ; S D=1) . \\
& * \mathrm{p} \leq .05
\end{aligned}
$$




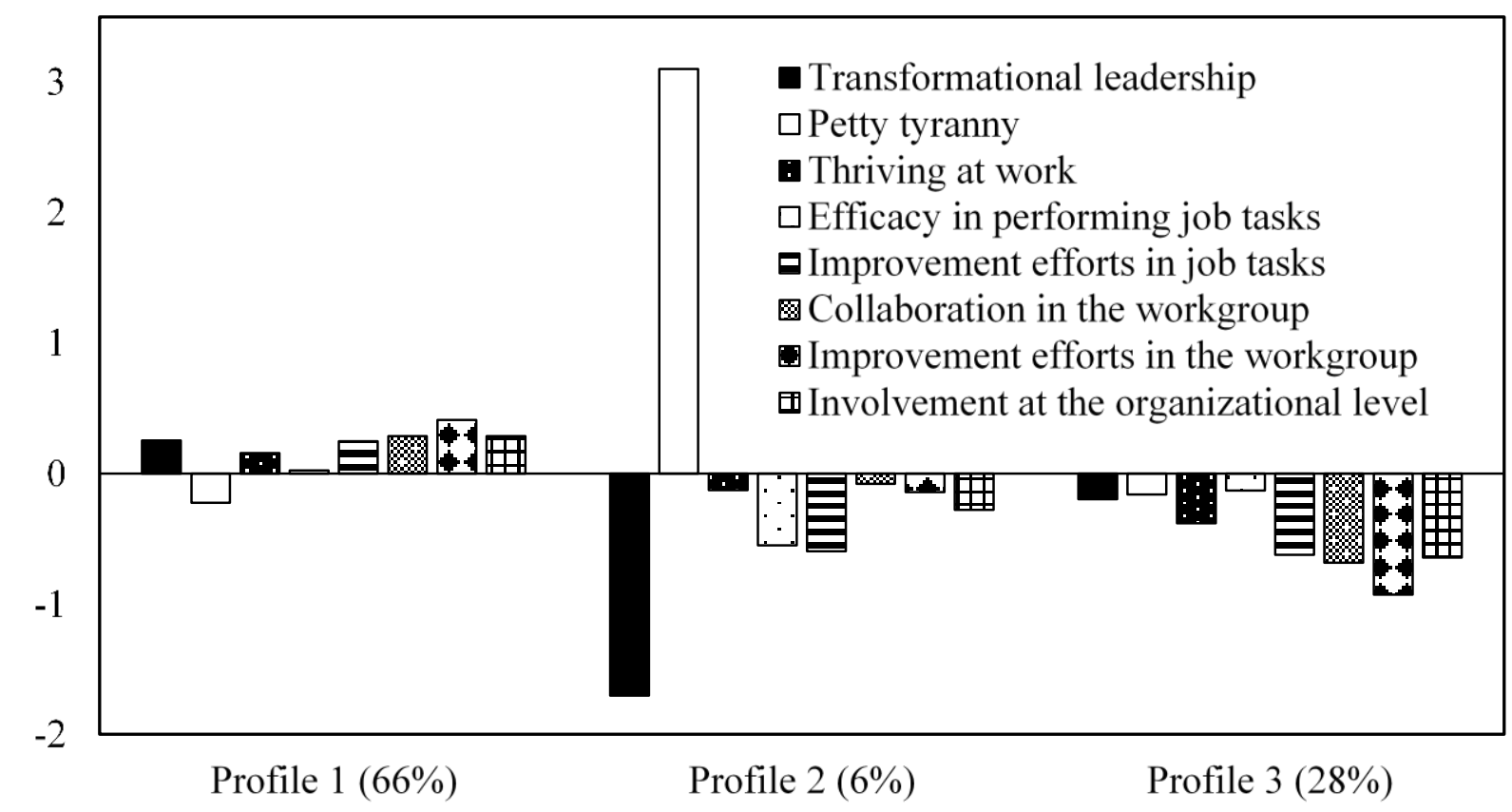

Figure 1. Profiles of Petty Tyranny and Transformational Leadership, Thriving at Work and Behavioral Empowerment; Note. Variables are factor scores estimated in standardized units $(M=0 ; S D=1)$. 


\section{Online Supplements For:}

The Combined Effects of Destructive and Constructive Leadership on Thriving at Work and Behavioral Empowerment 


\section{ONLINE SUPPLEMENTS FOR CONSTRUCTIVE AND DESTRUCTIVE LEADERSHIP}

\section{Preliminary Measurement Models}

Preliminary measurement models were estimated using Mplus 7.4's (Muthén \& Muthén, 2015) robust maximum likelihood estimator (MLR) and complex survey design function, which provides standard errors, tests of statistical significance, and tests of model fit that are robust to the non-normality and to the clustering of participants into 505 work units (e.g., Asparouhov, 2005; Marsh \& O'Mara, 2010). The relatively limited amount of missing responses present at the item level (1.59\% to $4.48 \%)$ was handled using full information maximum likelihood procedures (Enders, 2010).

Bifactor confirmatory factor analytic (CFA) models were used to represent the a priori representation of transformational leadership, petty tyranny, and thriving at work, which were all expected to reflect a global overarching construct (Chen et al., 2006; Morin et al., 2016). In contrast, the a priori behavioral empowerment representation was specified according to a classical 5-factor CFA. Bifactor CFA directly tests if item responses can be explained by an overarching global factor (e.g., transformational leadership), while simultaneously taking into account the existence of remaining specificity located at the subscale level (e.g., idealized influence, individual consideration, inspirational motivation). In these bifactor-CFA models, all items from each specific instrument were specified as loading simultaneously on this global factor, as well as on their specific subscales, and all factors were specified as orthogonal within each instrument, but allowed to correlate across instruments (Gignac, 2016; Morin et al., 2016). In contrast, the behavioral empowerment CFA factors were allowed to correlate with one another, as well as with the factors from the other instruments.

This a priori measurement model resulted in a fully acceptable level of fit to the data: $\chi^{2}=3688.11 ; d f=1170 ;$ CFI = .96; TLI = .95; and RMSEA = .03 (Hu \& Bentler, 1999; Marsh et al., 2005). Parameter estimates and model-based composite reliability estimates ( $\omega$ : McDonald omega; McDonald, 1970) from this model are reported in Table $S 1$ of these online supplements. These parameter estimates supported the adequacy of the transformational leadership $(\lambda=.67$ to $.86 ; \omega=.97)$, petty tyranny $(\lambda=.66$ to .88 ; $\omega=.96)$, and thriving at work $(\lambda=.58$ to $.85 ; \omega=.92)$ global factors. Likewise, each behavioral empowerment dimension also shows adequate factor loadings and composite reliability $(\lambda=.64$ to $.95 ; \omega$ $=.79$ to .90$)$.

\section{References}

Asparouhov, T. 2005. Sampling weights in latent variable modeling. Structural Equation Modeling, 12(3), 411-434.

Chen, F. F., West, S. G., \& Sousa, K. H. 2006. A comparison of bifactor and second-order models of quality of life. Multivariate Behavioral Research, 41(2), 189-225.

Enders, C.K. 2010. Applied missing data analysis. Guilford Press.

Gignac, G. E. 2016. The higher-order model imposes a proportionality constraint: That is why the bifactor model tends to fit better. Intelligence, 55(2016), 57-68.

Hu, L.T., \& Bentler, P.M. 1999. Cut-off criteria for fit indexes in covariance structure analysis. Conventional criteria versus new alternatives. Structural Equation Modeling, 6(1), 1-55.

Marsh, H. W., Hau, K.-T., \& Grayson, D. (2005). Goodness of fit evaluation in structural equation modeling. In A. Maydeu-Olivares \& J. McArdle (Eds.), Multivariate applications book series. Contemporary psychometrics: A festschrift for Roderick P. McDonald (p. 275-340). Mahwah, NJ: Lawrence Erlbaum Associates Publishers.

Marsh, H. W., \& O’Mara, A. J. 2010. Long-term total negative effects of school-average ability on diverse educational outcomes. Zeitschrift für Pädagogische Psychologie, 24(1) 51-72.

McDonald, R.P. 1970. Theoretical foundations of principal factor analysis and alpha factor analysis. British Journal of Mathematical and Statistical Psychology, 23(1), 1-21.

Morin, A.J.S., Arens, A.K., \& Marsh, H.W. 2016. A bifactor exploratory structural equation modeling framework for the identification of distinct sources of construct-relevant psychometric multidimensionality. Structural Equation Modeling, 23(1) 1-24.

Muthén, L., \& Muthén, B. 2015. Mplus user's guide. Los Angeles, CA: Muthén \& Muthén. 
Table S1

Tables and Figure

Standardized Factor Loadings from the Preliminary Measurement Models

\begin{tabular}{|c|c|c|c|c|c|c|c|c|c|c|c|c|c|}
\hline \multirow[b]{2}{*}{ Items } & \multicolumn{4}{|c|}{ Transformational Leadership } & \multirow[b]{2}{*}{$\operatorname{TFLIM}(\lambda)$} & \multirow[b]{2}{*}{$\delta$} & \multirow[b]{2}{*}{ Items } & \multicolumn{6}{|c|}{ Behavioral Empowerment } \\
\hline & TFL $(\lambda)$ & TFLII $(\lambda)$ & $\operatorname{TFLIC}(\lambda)$ & TFLIS $(\lambda)$ & & & & $\operatorname{ET}(\lambda)$ & $\operatorname{IMPT}(\lambda)$ & $\operatorname{COLG}(\lambda)$ & $\operatorname{IMPG}(\lambda)$ & $\operatorname{INVO}(\lambda)$ & $\delta$ \\
\hline TFLII1 & .848 & .247 & & & & .221 & ET1 & .822 & & & & & .325 \\
\hline TFLII2 & .829 & .209 & & & & .269 & ET2 & .889 & & & & & .209 \\
\hline TFLII3 & .861 & .308 & & & & .164 & ET3 & .842 & & & & & .290 \\
\hline TFLII4 & .714 & .150 & & & & .467 & IMPT1 & & .901 & & & & .188 \\
\hline TFLII5 & .668 & -.267 & & & & .483 & IMPT2 & & .869 & & & & .244 \\
\hline TFLII6 & .749 & -.261 & & & & .371 & IMPT3 & & .832 & & & & .307 \\
\hline TFLII7 & .783 & .162 & & & & .360 & COLG1 & & & .678 & & & .541 \\
\hline TFLII8 & .790 & -.210 & & & & .331 & COLG2 & & & .742 & & & .449 \\
\hline TFLIC1 & .758 & & .210 & & & .381 & COLG3 & & & .813 & & & .339 \\
\hline TFLIC2 & .758 & & .059 & & & .422 & IMPG1 & & & & .918 & & .157 \\
\hline TFLIC3 & .718 & & .220 & & & .436 & IMPG2 & & & & .921 & & .151 \\
\hline TFLIC4 & .802 & & .458 & & & .147 & IMPG3 & & & & .643 & & .587 \\
\hline TFLIS1 & .679 & & & .106 & & .527 & INVO1 & & & & & .954 & .090 \\
\hline TFLIS2 & .789 & & & -.016 & & .377 & INVO2 & & & & & .846 & .284 \\
\hline TFLIS3 & .745 & & & .307 & & .351 & INVO3 & & & & & .755 & .430 \\
\hline TFLIS4 & .757 & & & .520 & & .156 & & & & & & & \\
\hline TFLIM1 & .686 & & & & .561 & .214 & & & & & & & \\
\hline TFLIM2 & .719 & & & & .343 & .365 & & & & & & & \\
\hline TFLIM3 & .799 & & & & .333 & .251 & & & & & & & \\
\hline TFLIM4 & .750 & & & & .007 & .438 & & & & & & & \\
\hline$\Omega$ & .972 & .041 & .393 & .373 & .550 & & & .888 & .902 & .790 & .873 & .890 & \\
\hline
\end{tabular}

Note. $\lambda$ : Loadings; $\delta$ : Uniquenesses; Non-statistically significant $(p>.05)$ parameter estimates are marked in italics; TFL: Transformational leadership; TFLII: Idealized influence; TFLIS: Intellectual stimulation; TFLIM: Inspirational motivation; TFLIC: Individualized consideration; ET: Efficacy-tasks; IMPT: Improvement-tasks; COLG: Collaboration-group; IMPG: Improvement-group; INVO: Involvement-organization; $\omega$ : composite reliability coefficients computed from the standardized parameter estimates, using McDonald's (1970) omega coefficient: $\omega=(\Sigma|\lambda \mathrm{i}|)^{2} /\left([\Sigma|\lambda \mathrm{i}|]^{2}+\Sigma \delta \mathrm{ii}\right)$ where $\lambda \mathrm{i}$ are the factor loadings and $\delta \mathrm{ii}$, the error variances. 
Table S1 (Continued)

Standardized Factor Loadings from the Preliminary Measurement Models

\begin{tabular}{|c|c|c|c|c|c|c|c|c|c|c|}
\hline \multirow[b]{2}{*}{ Items } & \multicolumn{5}{|c|}{ Petty tyranny } & \multicolumn{5}{|c|}{ Thriving at Work } \\
\hline & $\mathrm{PT}(\lambda)$ & $\operatorname{PTSA}(\lambda)$ & $\operatorname{PTNPC}(\lambda)$ & $\operatorname{PTDP}(\lambda)$ & $\delta$ & Items & $\operatorname{THRIV}(\lambda)$ & $\operatorname{VIT}(\lambda)$ & $\operatorname{LEA}(\lambda)$ & $\delta$ \\
\hline PTSA1 & .655 & .461 & & & .358 & VIT1 & .852 & .317 & & .173 \\
\hline PTSA2 & .789 & .378 & & & .234 & VIT2 & .708 & .489 & & .259 \\
\hline PTSA3 & .764 & .325 & & & .310 & VIT3 & .793 & .253 & & .307 \\
\hline PTSA4 & .754 & .397 & & & .274 & LEA1 & .581 & & .331 & .553 \\
\hline PTNCP1 & .669 & & .567 & & .231 & LEA2 & .781 & & .461 & .177 \\
\hline PTNCP2 & .734 & & .539 & & .171 & LEA3 & .840 & & .149 & .273 \\
\hline PTNCP3 & .686 & & .489 & & .291 & & & & & \\
\hline PTNCP4 & .686 & & .446 & & .330 & & & & & \\
\hline PTDP1 & .813 & & & .196 & .301 & & & & & \\
\hline PTDP2 & .882 & & & .156 & .197 & & & & & \\
\hline PTDP3 & .794 & & & -.004 & .370 & & & & & \\
\hline PTDP4 & .845 & & & -.211 & .242 & & & & & \\
\hline$\Omega$ & .961 & .674 & .803 & .017 & & & .923 & .603 & .469 & \\
\hline
\end{tabular}

Note. $\lambda$ : Loadings; $\delta$ : Uniquenesses; Non-statistically significant ( $\mathrm{p}>.05)$ parameter estimates are marked in italics; THRIV: Thriving at work; VIT: Vitality; LEA: Learning; $\omega$ : composite reliability coefficients computed from the standardized parameter estimates, using McDonald's (1970) omega coefficient: $\omega=(\Sigma|\lambda \mathrm{i}|)^{2} /\left([\Sigma|\lambda \mathrm{i}|]^{2}+\Sigma \delta \mathrm{ii}\right)$ where $\lambda \mathrm{i}$ are the factor loadings and $\delta \mathrm{ii}$, the error variances. 
Table S2

Classification Accuracy: Classification Probability for Most Likely Profile Membership (Column) as a Function of the Profile Membership (Row)

\begin{tabular}{llll}
\hline & Profile 2 & Profile 3 & Profile 1 \\
\hline Profile 2 & .950 & .011 & .039 \\
Profile 3 & .003 & .869 & .128 \\
Profile 1 & .002 & .032 & .966 \\
\hline
\end{tabular}

\section{Table S3}

Within-Profile Means and Variances on the Leadership Dimensions and Outcomes

\begin{tabular}{|c|c|c|c|c|c|c|}
\hline \multirow{2}{*}{ Mean [CI] } & \multicolumn{2}{|c|}{ Profile 1} & \multicolumn{2}{|c|}{ Profile 2} & \multicolumn{2}{|c|}{ Profile 3} \\
\hline & & & & & & \\
\hline Transformational & .252 & {$[.183 ; .321]$} & -1.702 & {$[-2.003 ;-1.401]$} & -.198 & {$[-.318 ;-.078]$} \\
\hline Petty tyranny & -.223 & {$[-.272 ;-.174]$} & 3.102 & {$[2.630 ; 3.574]$} & -.161 & {$[-.226 ;-.097]$} \\
\hline Thriving & .156 & {$[.093 ; .219]$} & -.129 & {$[-.784 ; .525]$} & -.381 & {$[-.505 ;-.257]$} \\
\hline Efficacy-Tasks & .023 & {$[-.051 ; .096]$} & -.550 & {$[-1.254 ; .154]$} & -.130 & {$[-.289 ; .030]$} \\
\hline Improvement-Tasks & .247 & {$[.191 ; .304]$} & -.596 & {$[-1.342 ; .151]$} & -.623 & {$[-.767 ;-.478]$} \\
\hline Collaboration-Group & .288 & {$[.231 ; .344]$} & -.078 & {$[-.598 ; .441]$} & -.684 & {$[-.833 ;-.535]$} \\
\hline Improvement-Group & .409 & {$[.338 ; .481]$} & -.143 & {$[-.676 ; .390]$} & -.929 & {$[-1.070 ;-.788]$} \\
\hline Involvement-Org. & .288 & {$[.197 ; .378]$} & -.279 & {$[-.887 ; .330]$} & -.646 & {$[-.766 ;-.527]$} \\
\hline \multicolumn{7}{|l|}{ Variance $[C I]$} \\
\hline Transformational & .711 & {$[.635 ; .787]$} & .711 & {$[.635 ; .787]$} & .711 & {$[.635 ; .787]$} \\
\hline Petty tyranny & .287 & {$[.231 ; .344]$} & .287 & {$[.231 ; .344]$} & .287 & {$[.231 ; .344]$} \\
\hline Thriving & .505 & {$[.445 ; .565]$} & 1.233 & {$[.873 ; 1.593]$} & .934 & {$[.793 ; 1.076]$} \\
\hline Efficacy-Tasks & .645 & {$[.573 ; .718]$} & .921 & {$[.745 ; 1.097]$} & 1.170 & {$[.924 ; 1.416]$} \\
\hline Improvement-Tasks & .373 & {$[.339 ; .406]$} & .676 & {$[.371 ; .981]$} & 1.186 & {$[1.024 ; 1.348]$} \\
\hline Collaboration-Group & .347 & {$[.319 ; .376]$} & .498 & {$[.379 ; .616]$} & .783 & {$[.704 ; .861]$} \\
\hline Improvement-Group & .375 & {$[.326 ; .424]$} & .539 & {$[.420 ; .658]$} & 677 & {$[.615 ; .739]$} \\
\hline Involvement-Org. & .703 & {$[.640 ; .767]$} & .710 & {$[.558 ; .863]$} & .697 & {$[.620 ; .775]$} \\
\hline
\end{tabular}

Note. CI $=95 \%$ confidence interval; Variables are factor scores estimated in standardized units $(M=0 ; S D=1)$. 


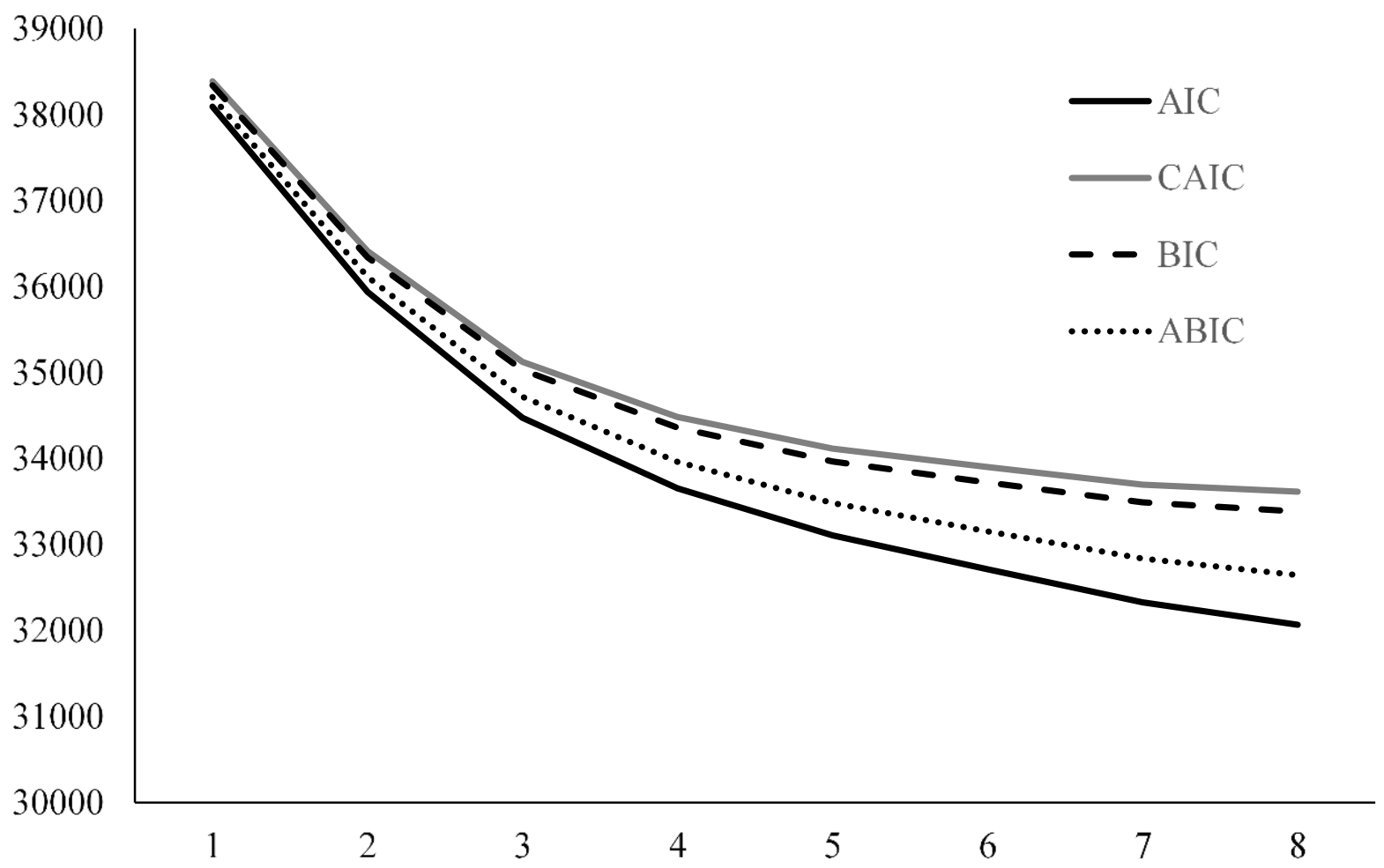

Figure S1. Elbow Plot of the Information Criteria for the Hybrid Mixture Regression Analyses. 